\title{
Adaptive cycles of floodplain vegetation response to flooding and drying
}

\author{
R. Thapa, M. C. Thoms, M. Parsons, and M. Reid \\ Riverine Landscapes Research Laboratory, Geography and Planning, University of \\ New England, NSW, 2351, Australia \\ Correspondence to: R. Thapa (thapa.rajesh@gmail.com)
}

Received: 17 July 2015 - Published in Earth Surf. Dynam. Discuss.: 2 September 2015

Revised: 7 December 2015 - Accepted: 2 January 2016 - Published: 3 February 2016

\begin{abstract}
Flooding is a key driver of floodplain vegetation productivity. Adaptive cycles provide a model for examining the productivity of semi-arid floodplain vegetation in response to hydrology. We examined the response of vegetation productivity (measured as NDVI) through a hypothesised adaptive cycle to determine whether the cycle repeats over time and how it is affected by differently sized flood events. The area of floodplain inundation was associated with an adaptive cycle that repeated in four flood events through the following phases: wetting (exploitation phase), wet (conservation phase), drying (release phase) and dry (reorganisation phase). Vegetation productivity responses corresponded to these phases. The area and quality of floodplain vegetation productivity followed the hypothesised pattern of higher-quality vegetation vigour in the wetting and wet phases, lower vigour in the drying phase and lowest vigour in the dry phase. There were more transitions between NDVI classes in the wet phase, which was dominated by two-way transitions. Overall, the wetting, wet and drying phases were dominated by smaller-probability class changes, whereas in the dry phase, higher-probability class changes were more prominent. Although the four flood events exhibited an adaptive cycle the duration of the adaptive-cycle phases, and the nature of vegetation productivity response, differed with the character of the flood event. Vegetation response in two of the adaptive-cycle phases - the release and reorganisation phases - were as hypothesised, but in the exploitation and conservation phases, changes in vegetation productivity were more dynamic. The character of vegetation response through the adaptive cycle also indicates that semi-arid floodplain vegetation productivity is more vulnerable to changing state during the conservation and release phases and not during the exploitation and reorganisation phases as resilience theory suggests. Overall, the adaptive cycle represents a new model to improve our understanding of the complexity of change in semi-arid floodplain vegetation productivity through cycles of flooding and drying. Changes in vegetation productivity could initiate structural changes in floodplain vegetation communities, with commensurate influences on floodplain sediment dynamics.
\end{abstract}

\section{Introduction}

Floodplains are dynamic features of the riverine landscape driven by exchanges of water and sediment mediated by the presence of vegetation (Hupp, 2000; Naiman et al., 2010). This occurs on multiple temporal and spatial scales (Dollar et al., 2007). Feedbacks that occur between water, sediment and vegetation on the floodplain surface are indicative of complex adaptive systems, which are characterised by multiple stable states, nonlinear dynamics, fast and slow drivers and self-emergence (Holling, 1973; Holling and Gun- derson, 2002; Folke et al., 2010). However, change arising from the feedbacks between water, sediment and vegetation on the floodplain surface are rarely considered as a complex adaptive system, even though such an understanding is essential for advancing the study, modelling and management of floodplains as vital earth surface systems. Resilience theory proposes that change in landscapes and ecosystems can be viewed as an adaptive cycle with four phases - exploitation, conservation, release and reorganisation - that occur in sequence as a result of external influences and internal sys- 


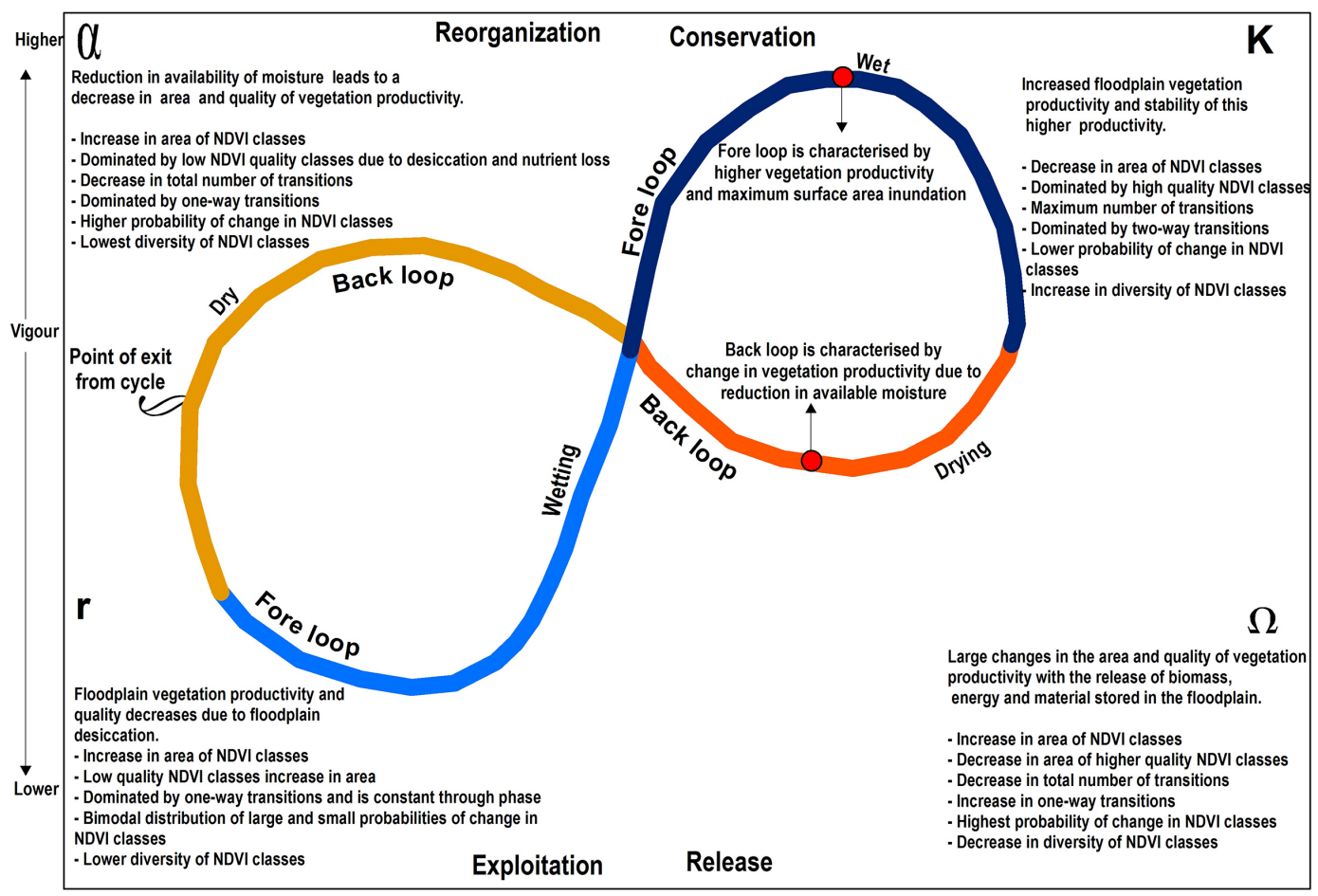

Dry floodplain $\longleftrightarrow$ Floodplain Inundation $\longrightarrow$ Complete inundation

Figure 1. The hypothesised adaptive-cycle model of vegetation productivity response to hydrology in semi-arid floodplains. The adaptive cycle starts as floodwater inundates the floodplain in the wetting phase (exploitation). The wet phase (conservation) is a period of maximum inundation, the drying phase (release) begins with the contraction of floodwaters, and the dry phase (reorganisation) occurs with the desiccation of the floodplain. The adaptive cycle reflects changes in two properties: (i) floodplain connectedness, which ranges from a totally dry to complete inundation of the floodplain along the $x$ axis, and (ii) vegetation productivity, ranging from low to high vegetation vigour along the $y$ axis. Exit from the cycle occurs within left quadrant of the figure and represents the stage where there is potential for a change in state or a flip to a new state. Figure taken from Thapa et al. (2016).

tem dynamics (Holling and Gunderson, 2002). The exploitation phase ( $r$ phase) occurs early in the adaptive cycle and follows a previous disturbance. In this phase, elements of the system are engaged in rapid growth to exploit available resources (Walker and Salt, 2006). Through the conservation phase ( $K$ phase), biomass gradually builds up and energy and materials accumulate in the system (Holling and Gunderson, 2002). The release phase ( $\Omega$ phase) is triggered by internal or external disturbances (Holling and Gunderson, 2002). In the release phase, biomass, energy and materials stored in the system are released, becoming available as the template for the reorganisation phase. In the reorganisation phase ( $\alpha$ phase), the system reorganises into the same state or may become vulnerable to flipping into a new state, which is likely to be organised differently and to be less productive (Holling and Gunderson, 2002). If the system does not flip into a new state, it moves back into the exploitation phase where a new cycle begins.

Semi-arid floodplains are ecosystems characterised by long periods of no or limited surface water interspersed by periods of floodplain inundation (Thoms, 2003). Flooding is a primary driver of floodplain productivity that can stimulate a rapid increase in vegetation productivity that may be maintained for months across large areas of floodplain (Capon, 2003; Reid et al., 2011; Parsons and Thoms, 2013). The productivity of floodplain vegetation in response to flooding has been hypothesised to be more complex than a simple boom-bust model and follow an adaptive cycle of exploitation, conservation, release and reorganisation (Thapa et al., 2016). There are two interacting elements of this hypothesised floodplain adaptive cycle (Fig. 1). The first describes the progression of flooding as the key driver of floodplain vegetation productivity through the adaptive cycle. The second describes the progression of vegetation productivity response to the driver through the phases of the adaptive cycle. Thus, the adaptive-cycle hypothesis proposes that floodplain ecosystem change is characterized by the relationship between the availability of floodplain surface water and vegetation productivity.

The hypothesis of Thapa et al. (2016) describes change in semi-arid floodplain vegetation productivity through an adaptive cycle with four phases: wetting, wet, drying and dry. The wetting and wet phases (exploitation to conservation), where the floodplain is wetted towards maximum inundation, 
is a period of enhanced vegetation productivity (Fig. 1). With maximum inundation, vegetation productivity is expected to decrease in total area but be higher in quality and stable in these aspects across the floodplain (Fig. 1). During the drying phase (release), surface water inundation contracts and the floodplain begins to dry (Fig. 1). Vegetation productivity is expected to not only decrease in area and quality in this phase but also have a higher probability of change in the area and quality of vegetation productivity because of the release of biomass, energy and material stored in the floodplain (Fig. 1). As the floodplain surface dries further, vegetation productivity moves into the dry phase (reorganisation), with vegetation productivity expected to decline even further in area and quality (Fig. 1). Some vegetation communities with access to remaining moisture may thrive in this phase; however, as the floodplain becomes desiccated during the dry phase, floodplain vegetation productivity is expected to be lower in area and quality and unstable. The highest likelihood of change to a new state should occur during the movement from the reorganisation to the exploitation phase (Holling and Gunderson, 2002). In the dry phase, floodplain vegetation may reorganise itself into the same state ready to begin a new cycle when flooding occurs or exit the cycle to flip into a different state (Fig. 1). Overall, the fore loop of the adaptive cycle (exploitation to conservation) is characterised by higher vegetation productivity and the back loop (release to reorganisation) is characterised by greater change in vegetation productivity because of the release of biomass and energy stored in the floodplain. In moving between the phases of the adaptive cycle the area of floodplain inundated varies from low to high (Fig. 1, $x$ axis), which corresponds to the connectedness of the system through an adaptive cycle. Vigour varies from low to high (Fig. 1, $y$ axis), which relates to the potential of the system through an adaptive cycle. Systems with low potential and low connectedness will have higher resilience and vice versa (Holling and Gunderson, 2002).

The hypothesis proposed by Thapa et al. (2016) is derived from observations of floodplain vegetation productivity through only one cycle of flooding and drying. However, unanswered questions remain about the efficacy of adaptive cycles for characterising floodplain vegetation productivity in response to different flooding and drying events. Floods, and therefore the character of floodplain inundation, differ in magnitude, timing, duration and spatial pattern (Murray et al., 2006; Thoms and Parsons, 2011). As these factors influence vegetation productivity responses (Capon, 2003; Parsons and Thoms, 2013), the passage of vegetation productivity around an adaptive cycle in response to flooding and drying might not occur in all floods, making the application of adaptive cycles untenable. This study examines adaptive cycles of floodplain vegetation in response to four flood events to determine whether an adaptive cycle repeats and how it is influenced by different-sized flood events.

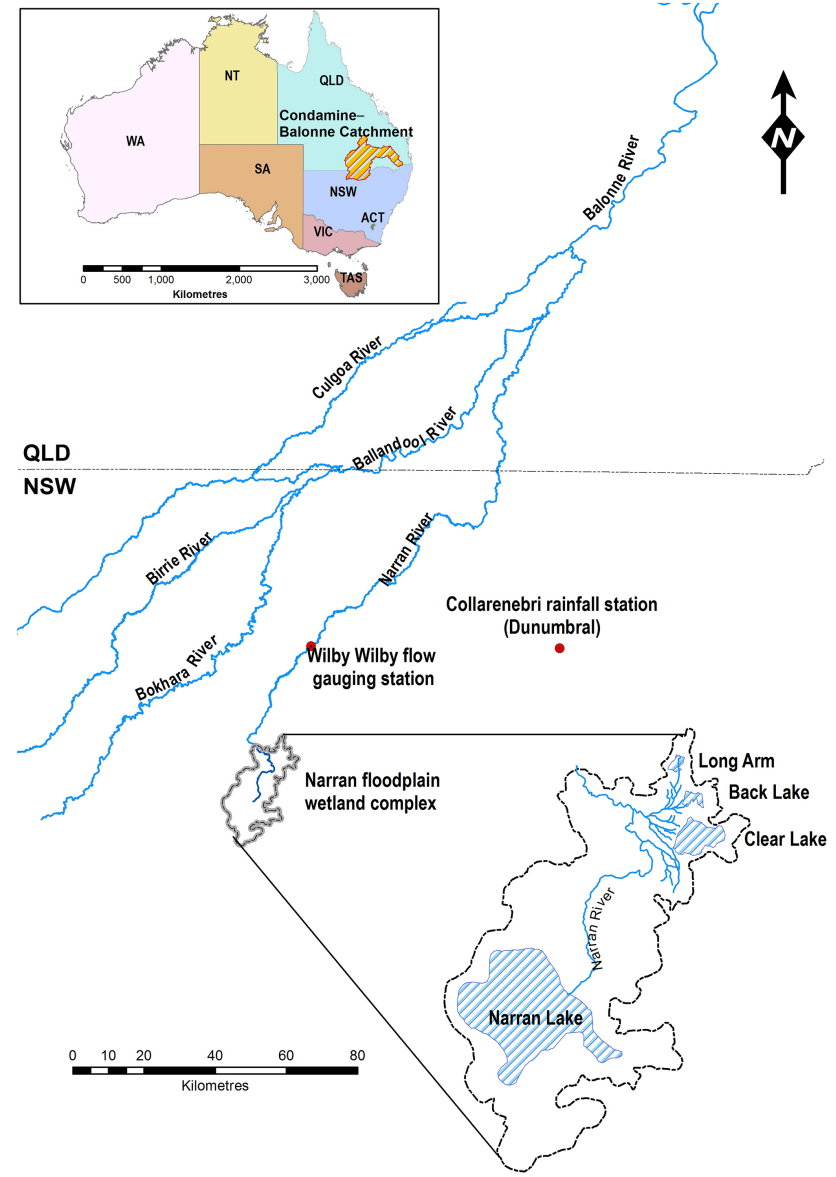

Figure 2. The Narran floodplain within the lower reaches of the Condamine-Balonne catchment, Australia.

\subsection{Study area}

The Narran floodplain is located in the Condamine-Balonne catchment, within the northern region of the Murray-Darling Basin, Australia (Fig. 2). The Condamine-Balonne River originates in well-watered uplands of the south-east Queensland highlands but flows for most part across a dry landscape (Thoms and Sheldon, 2000). The river has a single channel for most of its length but bifurcates into five anabranching channels downstream of St. George, known locally as the Lower Balonne (Fig. 2). These channels have relatively low gradients (0.0002 to 0.0003 ), are highly sinuous (1.9 to 2.5) and the bankfull cross-sectional area of each decreases with distance downstream (Thoms, 2003). The Narran River, which flows along the eastern boundary of the Lower Balonne, terminates within the Narran floodplain (Fig. 2).

The Narran floodplain covers $296 \mathrm{~km}^{2}$. It has regional, national and international importance as a Ramsar Convention site and $5.5 \mathrm{~km}^{2}(2 \%)$ of the floodplain landscape is managed as National Park. The local drainage area of the Narran floodplain is small $\left(50 \mathrm{~km}^{2}\right)$; therefore, the Narran floodplain 
is not inundated as a result of local rainfall but from flows in the Narran River (Rayburg and Thoms, 2009). Local rainfall is highly variable, with annual rainfall ranging from $144 \mathrm{~mm}$ (2002) to $957 \mathrm{~mm}$ (1950) at Collarenebri, and occurs mainly in the summer months (November-February) associated with tropical monsoonal activity. With a mean annual evaporation of $2250 \mathrm{~mm}$ the Narran floodplain landscape is dry most of the time. The Narran floodplain is geomorphologically complex with numerous lakes, channel networks and dissected floodplain surfaces (Rayburg and Thoms, 2009).

The long-term (1965-2009) mean annual discharge of the Narran River at Wilby Wilby (Gauge 422016) is $128717 \mathrm{ML}$, ranging from 1003 to $690000 \mathrm{ML}$. Flows exceeding $13000 \mathrm{ML}$ day $^{-1}$ (MLD) at Wilby Wilby result in overbank flows and inundation of the Narran floodplain (Rayburg and Thoms, 2009). These flows have an average recurrence interval of 1.5 years. The highly variable nature of flow in the Narran River results in infrequent periods of floodplain inundation (Murray et al., 2006). Inundation of the Narran floodplain is also spatially complex irrespective of the size of the flood event, with the expansion and contraction of floodwaters across the floodplain resulting in a dynamic mosaic of inundated patches (Murray et al., 2006). The relationship between floodplain inundated area and the number of inundated wet patches displays an anticlockwise hysteresis; therefore, significant fragmentation of floodwaters occurs during the contraction of floodwaters on the Narran floodplain (Murray et al., 2006).

The four main lakes of the Narran floodplain - Clear Lake, Back Lake, Long Arm and Narran Lake - (Fig. 2) hold water for different periods of time. Narran Lake $\left(51.95 \mathrm{~km}^{2}\right)$ has a capacity of $122500 \mathrm{ML}$ and retains water for up to $12-$ 15 months following a flood event but is dry $60 \%$ of the time (Rayburg and Thoms, 2009). Clear Lake $\left(5.86 \mathrm{~km}^{2}\right)$, Back Lake $\left(0.97 \mathrm{~km}^{2}\right)$ and Long Arm $\left(0.72 \mathrm{~km}^{2}\right)$ have a combined capacity of $17500 \mathrm{ML}$ and retain water for 4-12 months (Thoms et al., 2007). The northern part of the floodplain fills in sequence through Clear Lake, Back Lake, Long Arm (Fig. 2) and Narran Lake from flow in the Narran River (Rayburg and Thoms, 2009). The wetting and drying of the Narran floodplain has been severely impacted by water resource development in the upper catchment. Water extraction has reduced the median annual flow in the Narran River by approximately $30 \%$ (Thoms, 2003), significantly reducing moderate-sized floods on the Narran floodplain (Thoms et al., 2007).

Vegetation on the Narran floodplain is dominated by the perennial shrub lignum (Duma florulenta). Lignum shrubland is mostly found in the northern and central part of the floodplain along the Narran River. There is an overstorey of riparian woodland along main watercourses comprising river red gum (Eucalyptus camaldulensis), coolibah (Eucalyptus coolabah) and black box (Eucalyptus largiflorens). Other woodland species found in the Narran floodplain include poplar box (Eucalyptus populnea), belah ( $\mathrm{Ca}$ - suarina cristata), gidgee (Acacia calcicola), wilga (Geijera parviflora), black box (Eucalyptus largiflorens) and whitewood (Atalaya hemiglauca). Lignum shrubland and woodland communities cover approximately $151 \mathrm{~km}^{2}(51 \%)$ of the Narran floodplain. Grassland covers approximately $42 \mathrm{~km}^{2}$ (14\%) and consists of Mitchell grass (Astrebla spp.), neverfail (Eragrostis setifolia) and box grass (Paspalidium constrictum) interspersed among clumps of trees and shrubs. Crops and pastures cover $48 \mathrm{~km}^{2}(16 \%)$, and the remaining $55 \mathrm{~km}^{2}(19 \%)$ is lake area and barren ground.

\section{Methods}

\subsection{Satellite image selection}

Remotely sensed satellite images were used to track the productivity of vegetation through periods of flooding and drying in the Narran floodplain. A three-step process was used to obtain satellite images for the analysis of vegetation productivity. First, the conditions of dry and flood periods were defined. A dry period is a period of no flow or flow below the long-term 95th percentile flow, combined with below average rainfall. In a dry period there is no moisture subsidy to the floodplain through flooding or rainfall. Although groundwater can be an important source of moisture for floodplain vegetation in some contexts (Horner et al., 2009), groundwater in the Narran floodplain is approximately $100 \mathrm{~m}$ below the floodplain surface (Fitzpatrick et al., 2005). The flood period was defined as flow above 13000 MLD in the Narran River (Wilby Wilby), i.e. the flow required to initiate floodplain inundation (Thapa et al., 2016).

Second, discharge and rainfall records were searched for conditions matching the definition of dry and flood periods. Daily Narran River flow data (January 1980-December 2009 at Wilby Wilby) were acquired from the NSW Department of Primary Industries. Daily rainfall data for the same period were obtained from the Australian Bureau of Meteorology (Station 048038 at Collarenebri). Monthly discharge and rainfall means were calculated and each month in the record was delineated as being above or below average or as having no flow or rainfall. Periods fitting the definitions of flood and dry were identified in the discharge and rainfall record.

Third, the quality and existence of Landsat satellite imagery corresponding to the dry and flood periods were examined using the Geoscience Australia's Australian Centre for Remote Sensing (ACRES) and United States Geological Survey (USGS) catalogues. The Narran floodplain is encompassed in one Landsat scene (Path 92, Row 81). From the pool of high-quality satellite images, the years 1987, 1993, 2002 and 2007 for the dry period and 1988, 1994, 2004 and 2008 for the flood period were randomly selected. In each year, a sequence of images was selected at approximately monthly intervals. Care was taken to select high-quality images with no or minimum cloud cover. The dry period image sequence was stopped when rain occurred, and the flood 
period image sequence stopped when floodwater completely contracted and dry images started. The 75 dry and flood images were rearranged into four events. The details of images in each event are provided in Table 1.

Images were cropped to a standard floodplain area denoted by the boundary of floodplain soils (Rayburg et al., 2006). Images were resampled to $25 \mathrm{~m}$ resolution and reprojected to the Geodetic Datum of Australia 1994 Universal Transverse Mercator zone 55S, to ensure compatibility of images from different sources (i.e. from ACRES and USGS). The aligned image digital numbers were converted to top-of-atmosphere reflectance using the methods of Chander et al. (2009). A relative radiometric normalisation was performed using dark and light targets to make images acquired on different dates comparable (Myeong et al., 2006).

\subsection{Delineation of adaptive phases}

The flood period images were processed in ERDAS imagine software to delineate the expansion and contraction of flood waters across the floodplain. To map inundation extent, density slicing was used to identify inundated (water) and noninundated (non-water) pixels and their threshold reflectance values, as recommended by Overton (2005). In some images, detecting inundated pixels was not possible using a single band because of the presence of a dense vegetation canopy. For those images, the normalised difference water index $(\mathrm{Xu}, 2006)$ and unsupervised classification were used to differentiate between inundated and non-inundated pixels. These methods have been successfully used to map inundation across Australian floodplains using Landsat satellite imagery (Frazier and Page, 2000; Shaikh et al., 2001; Rayburg and Thoms, 2009; Thomas et al., 2010). The results from both methods were combined to estimate the area of floodplain inundation.

Phases of the adaptive cycle were delineated from the area of floodplain inundation. The wetting phase is an initial rapid expansion of floodwater across the floodplain. The wet phase is a period of maximum inundation. The drying phase is associated with the contraction of floodwaters and the dry phase is associated with no surface water availability. Differences in the area of floodplain inundation among the adaptive phases were examined for each event using nonparametric Kruskal-Wallis one-way analysis of variance on ranks in SigmaPlot (Version 12). Differences in the area of floodplain inundation among the four events were also examined using this test.

\subsection{Calculation of the normalised difference vegetation index}

The normalised difference vegetation index (NDVI) is based on the red and near-infrared (NIR) band reflectance properties and is strongly correlated with photosynthetic activity. Hence, NDVI is a surrogate for vegetation productivity
(Lillesand and Kiefer, 2000; Farina, 2006; Wen et al., 2012). The normalised difference vegetation index was calculated in each image as NDVI $=\rho \mathrm{NIR}-\rho \mathrm{red} / \rho \mathrm{NIR}+\rho$ red, where $\rho$ represents the spectral reflectance values of spectral bands NIR (band 4) and red (band 3) of Landsat Thematic Mapper (TM) and Enhanced Thematic Mapper Plus $(\mathrm{ETM}+)$ images. Entropy analysis and moving window analysis were used to divide the NDVI values of all 473142 pixels into classes, following the method of Parsons and Thoms (2013). Six NDVI classes emerged. Class 1 is no greenness (NDVI <0). Class 2 (NDVI 0-0.072), Class 3 (NDVI 0.072-0.207), Class 4 (NDVI 0.207-0.459), Class 5 (NDVI 0.459-0.666) and Class 6 (NDVI > 0.666) represent a continuum of increasing vegetation productivity.

\subsection{Analysis of vegetation productivity among adaptive-cycle phases}

Each image was allocated to the corresponding wetting, wet, drying or dry phase of the adaptive cycle. Four broad types of NDVI data were used to explore vegetation productivity through the dry, wetting, wet and drying phases: area and quality of NDVI; number and direction of NDVI class transitions; probability of NDVI class transitions; and NDVI class diversity. The area of floodplain with active vegetation productivity (total area of NDVI Classes 2-6) was calculated for each image. Quality of vegetation productivity was calculated as the area of individual NDVI classes in each image, where low-quality productivity is NDVI Class 2 and 3 (low greenness) and high-quality productivity is NDVI Classes 4 , 5 or 6 (higher greenness). NDVI Class 1 was excluded because this class has no greenness and corresponds to water bodies and barren ground.

Pairwise transitions between NDVI classes were calculated on a pixel-by-pixel basis between sequential images. Each pixel was assigned to a change class $\left(C_{i j}\right)$, which represents a change from NDVI class $i$ to NDVI class $j$. A total of $36 C_{i j}$ were possible among the 6 NDVI classes, comprising 6 constant classes and 30 directional change classes. First-order Markovian transition models (Weng, 2002; Bolliger et al., 2009) were used to model the number and direction of NDVI class transitions and the probability of NDVI class transitions between sequential images (termed a period). The Markovian transition model consists of the area of each NDVI change classes $\left(C_{i j}\right)$ present in each period and the probability $\left(P_{i j}\right)$ of each $C_{i j}$ occurring. Periods were allocated to the corresponding wetting, wet, drying or dry phase. The number of transitions and the direction of transitions (one-way or two-way) between NDVI classes were tallied from a pictorial representation of the Markovian transition model. Probability of change $\left(P_{i j}\right)$ was calculated as the proportion (\%) of the total number of NDVI classes $i$ that transitioned to NDVI Class $j$. The probabilities of transition were divided into six classes: $<1,1-5,5-10,10-20$, $20-30$ and $>50 \%$. The diversity of NDVI classes in each 
Table 1. Satellite images for the four events, with corresponding hydrology, rainfall and temperature conditions. A period refers to the comparison of two images, where the comparison of image 1 and 2 becomes Period 1. Hydrology data were obtained from the Department of Primary Industries (NSW) Office of Water Information, and climatic data were acquired from the Australian Bureau of Meteorology.

\begin{tabular}{|c|c|c|c|c|c|c|c|}
\hline $\begin{array}{l}\text { Date of } \\
\text { image }\end{array}$ & Image number & Period & $\begin{array}{r}\text { Dry or } \\
\text { flood image }\end{array}$ & Event & $\begin{array}{r}\text { Total } \\
\text { flow (MLD) }\end{array}$ & $\begin{array}{r}\text { Total } \\
\text { monthly } \\
\text { rainfall }(\mathrm{mm})\end{array}$ & $\begin{array}{r}\text { Mean monthly } \\
\text { maximum } \\
\text { temperature }\left({ }^{\circ} \mathrm{C}\right)\end{array}$ \\
\hline 27 May 1987 & 1 & & Dry & 1 & 0 & 82 & 22 \\
\hline 31 August 1987 & 2 & 1 & Dry & 1 & 2924 & 60 & 20 \\
\hline 9 October 1987 & 3 & 2 & Dry & 1 & 0 & 42 & 27 \\
\hline 21 December 1987 & 4 & 3 & Dry & 1 & 3862 & 75 & 35 \\
\hline 6 January 1988 & 5 & & Flood & 1 & 1156 & 32 & 37 \\
\hline 7 February 1988 & 6 & 4 & Flood & 1 & 3712 & 31 & 32 \\
\hline 23 February 1988 & 7 & 5 & Flood & 1 & 3712 & 31 & 32 \\
\hline 26 March 1988 & 8 & 6 & Flood & 1 & 65717 & 50 & 31 \\
\hline 13 May 1988 & 9 & 7 & Flood & 1 & 135747 & 19 & 22 \\
\hline 29 May 1988 & 10 & 8 & Flood & 1 & 135747 & 19 & 22 \\
\hline 16 July 1988 & 11 & 9 & Flood & 1 & 54725 & 92 & 19 \\
\hline 4 October 1988 & 12 & 10 & Flood & 1 & 1608 & 1 & 32 \\
\hline 20 October 1988 & 13 & 11 & Flood & 1 & 0 & 1 & 32 \\
\hline 21 November 1988 & 14 & 12 & Flood & 1 & 0 & 21 & 31 \\
\hline 23 December 1988 & 15 & 13 & Flood & 1 & 0 & 24 & 35 \\
\hline 8 January 1989 & 16 & 14 & Flood & 1 & 0 & 3 & 34 \\
\hline 9 February 1989 & 17 & 15 & Flood & 1 & 0 & 2 & 35 \\
\hline 14 April 1989 & 18 & 16 & Flood & 1 & 30648 & 60 & 26 \\
\hline 8 March 1993 & 19 & & Dry & 2 & 0 & 77 & 38 \\
\hline 9 April 1993 & 20 & 17 & Dry & 2 & 169 & 0 & 30 \\
\hline 25 April 1993 & 21 & 18 & Dry & 2 & 169 & 0 & 30 \\
\hline 11 May 1993 & 22 & 19 & Dry & 2 & 0 & 24 & 24 \\
\hline 12 June 1993 & 23 & 20 & Dry & 2 & 0 & 20 & 18 \\
\hline 28 June 1993 & 24 & 21 & Dry & 2 & 0 & 20 & 18 \\
\hline 14 July 1993 & 25 & 22 & Dry & 2 & 0 & 69 & 19 \\
\hline 3 November 1993 & 26 & 23 & Dry & 2 & 0 & 3 & 38 \\
\hline 7 February 1994 & 27 & & Flood & 2 & 6335 & 13 & 32 \\
\hline 23 February 1994 & 28 & 24 & Flood & 2 & 18315 & 13 & 32 \\
\hline 28 April 1994 & 29 & 25 & Flood & 2 & 0 & 0 & 27 \\
\hline 14 May 1994 & 30 & 26 & Flood & 2 & 0 & 0 & 23 \\
\hline 15 June 1994 & 31 & 27 & Flood & 2 & 0 & 0 & 20 \\
\hline 1 July 1994 & 32 & 28 & Flood & 2 & 0 & 0 & 19 \\
\hline 17 July 1994 & 33 & 29 & Flood & 2 & 0 & 0 & 19 \\
\hline 2 August 1994 & 34 & 30 & Flood & 2 & 0 & 0 & 21 \\
\hline 3 September 1994 & 35 & 61 & Flood & 2 & 0 & 0 & 24 \\
\hline 19 September 1994 & 36 & 32 & Flood & 2 & 0 & 0 & 24 \\
\hline 21 October 1994 & 37 & 33 & Flood & 2 & 0 & 12 & 29 \\
\hline 22 November 1994 & 38 & 34 & Flood & 2 & 0 & 85 & 31 \\
\hline 20 January 2002 & 39 & & Dry & 3 & 0 & 0 & 37 \\
\hline 5 February 2002 & 40 & 35 & Dry & 3 & 0 & 30 & 34 \\
\hline 9 March 2002 & 41 & 36 & Dry & 3 & 0 & 4 & 33 \\
\hline 10 April 2002 & 42 & 37 & Dry & 3 & 0 & 34 & 30 \\
\hline 28 May 2002 & 43 & 38 & Dry & 3 & 997 & 0 & 23 \\
\hline 29 June 2002 & 44 & 39 & Dry & 3 & 6 & 17 & 20 \\
\hline 15 July 2002 & 45 & 40 & Dry & 3 & 0 & 0 & 20 \\
\hline 16 August 2002 & 46 & 41 & Dry & 3 & 0 & 12 & 23 \\
\hline 17 September 2002 & 47 & 42 & Dry & 3 & 0 & 19 & 26 \\
\hline 19 October 2002 & 48 & 43 & Dry & 3 & 0 & 7 & 31 \\
\hline 4 November 2002 & 49 & 44 & Dry & 3 & 0 & 6 & 37 \\
\hline 6 December 2002 & 50 & 45 & Dry & 3 & 0 & 15 & 36 \\
\hline 18 January 2004 & 51 & & Flood & 3 & 8679 & 104 & 36 \\
\hline 3 February 2004 & 52 & 46 & Flood & 3 & 18199 & 26 & 36 \\
\hline 19 February 2004 & 53 & 47 & Flood & 3 & 18199 & 123 & 36 \\
\hline 23 April 2004 & 54 & 48 & Flood & 3 & 407 & 27 & 29 \\
\hline 9 May 2004 & 55 & 49 & Flood & 3 & 0.44 & 25 & 22 \\
\hline 10 June 2004 & 56 & 50 & Flood & 3 & 0 & 10 & 20 \\
\hline 12 July 2004 & 57 & 51 & Flood & 3 & 0 & 31 & 18 \\
\hline 14 September 2004 & 58 & 52 & Flood & 3 & 0 & 19 & 25 \\
\hline 16 October 2004 & 59 & 53 & Flood & 3 & 0 & 15 & 30 \\
\hline 17 November 2004 & 60 & 54 & Flood & 3 & 0 & 108 & 32 \\
\hline 19 December 2004 & 61 & 55 & Flood & 3 & 1115 & 107 & 33 \\
\hline 26 January 2007 & 62 & 56 & Dry & 4 & 0 & 33 & 37 \\
\hline 27 February 2007 & 63 & 57 & Dry & 4 & 0 & 76 & 36 \\
\hline 16 April 2007 & 64 & 58 & Dry & 4 & 0 & 30 & 29 \\
\hline 2 May 2007 & 65 & 59 & Dry & 4 & 0 & 50 & 24 \\
\hline 23 September 2007 & 66 & 0 & Dry & 4 & 8 & 27 & 59 \\
\hline 13 January 2008 & 67 & & Flood & 4 & 6607 & 63 & 33 \\
\hline 14 February 2008 & 68 & 60 & Flood & 4 & 21164 & 65 & 31 \\
\hline 17 March 2008 & 69 & 61 & Flood & 4 & 0 & 14 & 31 \\
\hline 2 April 2008 & 70 & 62 & Flood & 4 & 10000 & 0 & 26 \\
\hline 9 September 2008 & 71 & 63 & Flood & 4 & 0 & 68 & 25 \\
\hline 25 September 2008 & 72 & 64 & Flood & 4 & 0 & 68 & 25 \\
\hline 27 October 2008 & 73 & 65 & Flood & 4 & 0 & 57 & 30 \\
\hline 11 November 2008 & 74 & 66 & Flood & 4 & 0 & 98 & 30 \\
\hline 30 December 2008 & 75 & 67 & Flood & 4 & 0 & 32 & 35 \\
\hline
\end{tabular}




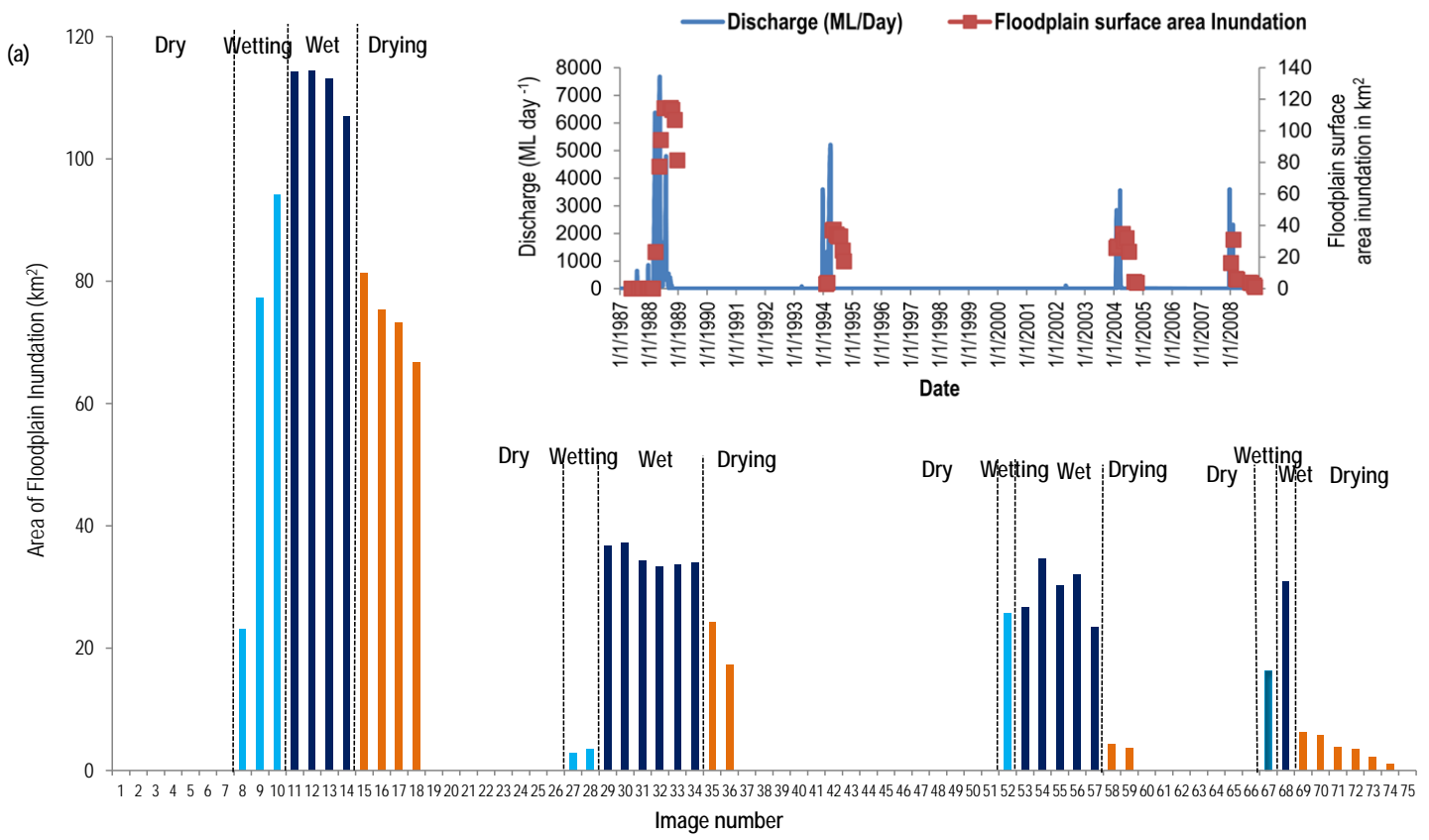

Figure 3. Surface area inundation of the Narran floodplain divided into corresponding dry, wetting, wet and drying phases of the adaptive cycle (a). Image numbers are explained in Table 1. Inset graph (b) shows the total discharge (ML) in the Narran River and the corresponding Narran floodplain surface area inundation.

image was also calculated using the Shannon-Wiener diversity index (Magurran, 1988). Monthly images are considered to be samples, NDVI classes species, and NDVI area abundance.

Differences in the total area of NDVI, area of each NDVI class, total transitions, one-way transitions, two-way transitions, probability of transitions and diversity among adaptive phases were examined separately using a non-parametric Kruskal-Wallis one-way analysis of variance on ranks in SigmaPlot (Version 12). The same test was also used to examine differences in these variables among flood events. The $H$ statistic is a measure of the actual difference in the sum of the ranking between samples. Multivariate analyses were used to examine differences among adaptive phases, using PRIMER_E and PERMANOVA+. Three types of data (area and quality, number and direction of transitions, probability of transitions) were analysed separately, but the four events were combined. Multi-dimensional scaling was performed using the Bray-Curtis similarity coefficient. The relative dispersion of images within an adaptive phase was examined using the multi-variate dispersion (MVDSP) routine (Warwick and Clarke, 1993), where lower values indicate similarity of images from the same adaptive phase in multivariate space. The relative dispersion among adaptive phases was examined using the distance among centroid routines in PERMANOVA+, which calculates distances among group centroids (Anderson et al., 2008). Lower values indicate closer centroids and, hence, greater similarity among adaptive phases.

\section{Results}

\subsection{Floodplain inundation and adaptive-cycle phases}

The area of floodplain inundation corresponds to the dry, wetting, wet and drying phases of an adaptive cycle. The adaptive cycle commences with an initial rapid expansion of floodwaters across the floodplain in the wetting phase (Fig. 3a). The wetting phase is followed by the wet phase, during which inundation is at its maximum extent, remaining relatively stable within the phase (Fig. 3a). The wet phase is followed by the drying phase, during which the area of inundated floodplain contracts (Fig. 3a). The dry phase follows the drying of the floodplain and remains in place until a flow event starts the next wetting phase. During the dry phase, surface water is absent from the floodplain (Fig. 3a). There was a significant difference in the area of floodplain inundation among the wetting, wet, drying and dry phases in each event (Event 1: $H=15.793, p=0.001$; Event 2: $H=16.309, p=<0.001$; Event 3: $H=19.480$, $p=<0.001$; Event $4: H=12.005, p=0.007)$. Thus, the divisions among phases are repeated across the four events.

Although the four events exhibit an adaptive cycle, the duration of each phase and the area inundated differed between events. Event 1 was characterised by phases of relatively similar duration; where wetting took approximately 3 months, the wet phase occurred for 4 months while the drying phase occurred over 4 months (Fig. 3a). In contrast, Events 2 and 3 were characterised by short wetting and drying phases of 


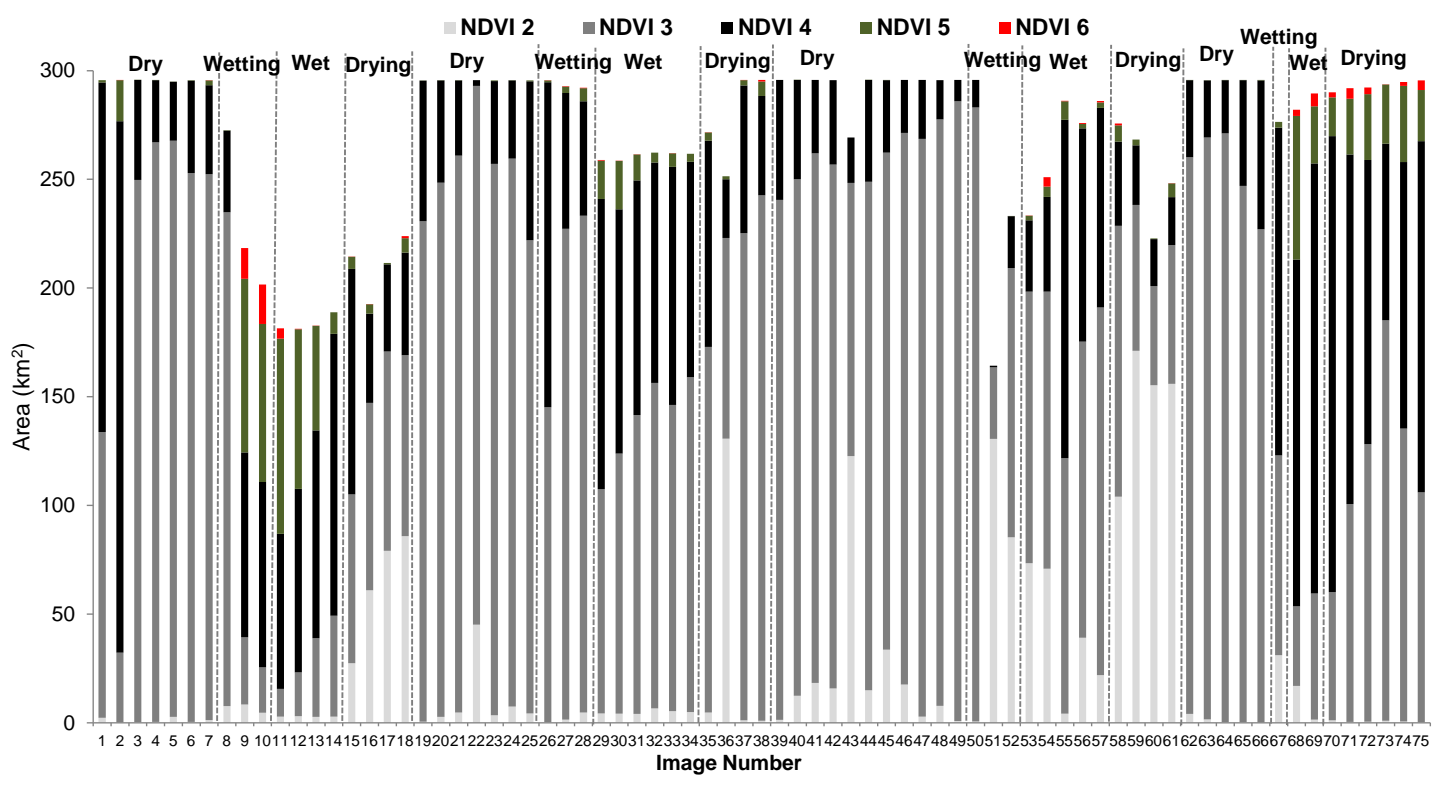

Figure 4. Area of NDVI Class 2 through to 6 in the Narran floodplain during the dry, wetting, wet and drying phases of the adaptive cycle. NDVI Class 1 is not shown because it represents bare ground or water. Image numbers are explained in Table 1.

approximately 2 months and a long wet phase of 6 months (Fig. 3a). Event 4 was very different from the other events and was characterised by a short wetting and wet phase of 1 month and an extended drying phase of over 6 months (Fig. 3a). There was a significant difference in inundated area among the four flood events $(H=8.507, p=0.037)$, related to flow in the Narran River. The largest area of floodplain inundation occurred in Event $1\left(114 \mathrm{~km}^{2}\right)$ and was associated with inflows that peaked at 135747 MLD in May 1988 (Fig. 3a and b). The second-largest floodplain inundation of $37 \mathrm{~km}^{2}$ occurred in Event 2 and was associated with a peak flow of 88974 MLD in March 1994. Floodplain inundation in Event 3 and Event 4 was associated with flows of 21307 MLD and 21164 MLD, resulting in inundation of $34 \mathrm{~km}^{2}$ and $31 \mathrm{~km}^{2}$ respectively (Fig. $3 \mathrm{a}$ and b). Overall, these differences largely reflect the hydrograph for each event, where larger floods are associated with some phases having a longer duration (Fig. 3b). Despite differences in the area of floodplain inundation between events and the length of the wetting, wet and drying phases, there is always a wetting, wet, drying and dry phase. Thus, vegetation productivity can be further examined in relation to the adaptive-cycle phases of floodplain inundation.

\subsection{Area and quality of vegetation productivity through the adaptive-cycle phases}

The total area of NDVI followed the hypothesised pattern (Fig. 1) of an increase in the dry and drying phases and decrease in the wetting and wet phases. In most events there was a significant difference in the total area of NDVI among the dry, wetting, wet and drying phases of the adaptive cycle
(Table 2). The total area of NDVI was always higher in the dry phase than the other phases (Fig. 4). Across all events the mean area of NDVI in the dry phase was $288 \mathrm{~km}^{2}$ (range: 164 to $296 \mathrm{~km}^{2}$ ). For comparison, the mean area of NDVI in the wetting phase was $255 \mathrm{~km}^{2}$ (range: 202 to $293 \mathrm{~km}^{2}$ ), the wet phase was $246 \mathrm{~km}^{2}$ (range: 181 to $286 \mathrm{~km}^{2}$ ) and the drying phase was $268 \mathrm{~km}^{2}$ (range: 193 to $296 \mathrm{~km}^{2}$ ).

As hypothesised in the adaptive-cycle model (Fig. 1) the highest-quality NDVI (Class 6) occurred mostly in the wetting and wet adaptive phases (Fig. 4). NDVI Class 6 did not occur in any dry phase across the four events (Fig. 4) as hypothesised. In contrast to the model, higher-quality NDVI did occur in the drying phase of Events 1 and 4, although the area of NDVI Class 6 was relatively low (Fig. 4). This was presumably because of additional water being available in both events: through the large magnitude of inflow in Event 1 and the contribution of managed environmental water in Event 4 (Table 1).

In most events there was a significant difference in NDVI quality (i.e. individual NDVI classes) between the wetting, wet, drying and dry adaptive phases (Table 2). During the dry phase, most of the floodplain was associated with NDVI Class 3 (Fig. 4) with a mean floodplain area across all events of $232 \mathrm{~km}^{2}$ (range: 32 to $285 \mathrm{~km}^{2}$ ). The next largest class was NDVI Class 4 (mean area of $47 \mathrm{~km}^{2}$; range: 0.7 to $244 \mathrm{~km}^{2}$ ), followed by NDVI Class 2 (mean $14 \mathrm{~km}^{2}$; range: 0.12 to $131 \mathrm{~km}^{2}$ ) and NDVI Class 5 (mean $0.76 \mathrm{~km}^{2}$; range: 0.01 to $19 \mathrm{~km}^{2}$ ) (Fig. 4). NDVI Class 3 was dominant in the wetting phase with a mean area of $136 \mathrm{~km}^{2}$, while in the wet phase, NDVI Classes 3 and 4 were dominant with a mean floodplain area of 101 and $102 \mathrm{~km}^{2}$ respectively. In the wetting and wet 
Table 2. Differences in NDVI class area and quality, number and direction of NDVI class transitions, probability of NDVI class transitions, and NDVI class diversity among adaptive-cycle phases of four events. NS: not significant $(p>0.05)$.

\begin{tabular}{|c|c|c|c|c|}
\hline \multirow[b]{2}{*}{ Data type } & \multicolumn{4}{|c|}{$p$ value } \\
\hline & Event 1 & Event 2 & Event 3 & Event 4 \\
\hline \multicolumn{5}{|l|}{ Area and quality } \\
\hline Total area of active NDVI & 0.002 & 0.016 & 0.003 & NS \\
\hline NDVI Class 2 & 0.002 & NS & 0.017 & NS \\
\hline NDVI Class 3 & 0.021 & 0.014 & 0.003 & NS \\
\hline NDVI Class 4 & NS & 0.031 & 0.044 & 0.004 \\
\hline NDVI Class 5 & 0.027 & 0.002 & 0.002 & 0.005 \\
\hline NDVI Class 6 & NS & 0.026 & 0.006 & 0.007 \\
\hline \multicolumn{5}{|l|}{ Number and direction of transitions } \\
\hline One-way transitions & NS & NS & NS & NS \\
\hline Two-way transitions & 0.004 & 0.010 & $<0.001$ & 0.016 \\
\hline Total transitions & 0.005 & 0.006 & $<0.001$ & 0.004 \\
\hline \multicolumn{5}{|l|}{ Probability of transitions (\%) } \\
\hline Number of transitions with probability $<1$ & 0.020 & NS & $<0.001$ & NS \\
\hline Number of transitions with probability 1 to 5 & 0.007 & 0.009 & $<0.001$ & NS \\
\hline Number of transitions with probability 5 to 10 & NS & NS & 0.008 & NS \\
\hline Number of transitions with probability 10 to 20 & 0.0045 & 0.043 & 0.004 & NS \\
\hline Number of transitions with probability 20 to 50 & 0.041 & NS & 0.024 & NS \\
\hline Number of transitions with probability $>50$ & NS & NS & NS & NS \\
\hline \multicolumn{5}{|l|}{ Diversity } \\
\hline Diversity of NDVI class area & 0.004 & 0.005 & 0.004 & NS \\
\hline
\end{tabular}

phases all six NDVI classes were present. The drying phase was also dominated by NDVI Classes 3 and 4, with mean areas of 119 and $94 \mathrm{~km}^{2}$ respectively, and all NDVI classes were present in this phase. Thus, in the wetting, wet and drying phases the quality of NDVI was consistent in all events with an increase and decrease in quality as hypothesised in the model. However, the quality of NDVI was expected to decrease in the dry adaptive phase, but this was not observed and it remained in Class 3 in this phase in all events (Fig. 4).

Ordination revealed some separation of images among the four phases of the adaptive cycle based on area of the NDVI classes (Fig. 5a). The dry images were clumped in multivariate space, whereas the wetting, wet and drying images were more dispersed (Table 3). The greatest distance among centroids was between the dry adaptive phase and the wetting, wet and drying adaptive phases (Table 4). The wetting-, wet- and drying-phase centroids were relatively close to each other in multivariate space (Table 4).

\subsection{Number and direction of transitions through the adaptive-cycle phases}

The observed pattern of the total number of NDVI class transitions followed the hypothesised adaptive-cycle model. In all events there was a significant difference in the total num-
Table 3. Multivariate dispersion (MVDSP) index values of the different adaptive-cycle phases for NDVI class area and quality, number and direction of NDVI class transitions, and probability of NDVI class transitions data.

\begin{tabular}{lrrrr}
\hline \multirow{2}{*}{ Data type } & \multicolumn{4}{c}{ Multivariate dispersion index } \\
\cline { 2 - 5 } & Dry & Wetting & Wet & Drying \\
\hline Area and quality & 0.89 & 1.34 & 1.29 & 1.29 \\
Number and direction of transitions & 0.75 & 1.63 & 1.29 & 1.28 \\
Probability of transitions & 1.28 & 0.38 & 0.72 & 0.67 \\
\hline
\end{tabular}

ber of transitions among the wetting, wet, drying and dry phases of the adaptive cycle (Table 2). In the dry phase 295 transitions occurred compared to 851 transitions in the combined wetting, wet and drying phases (Fig. 6). There was a marked increase in the total number of transitions during the wet and wetting phases followed by a decrease during the drying phase, with the lowest number of transitions in the dry phase (Fig. 6).

The average number of transitions in the dry phase was 11 (range: 4-18). For comparison, the average number of transitions was greater in the wet phase (average: 25; range: 19 30 ) followed by the wetting and drying phases (average: 19; range: $16-22$; average: 17 ; range: $15-26$ respectively). 


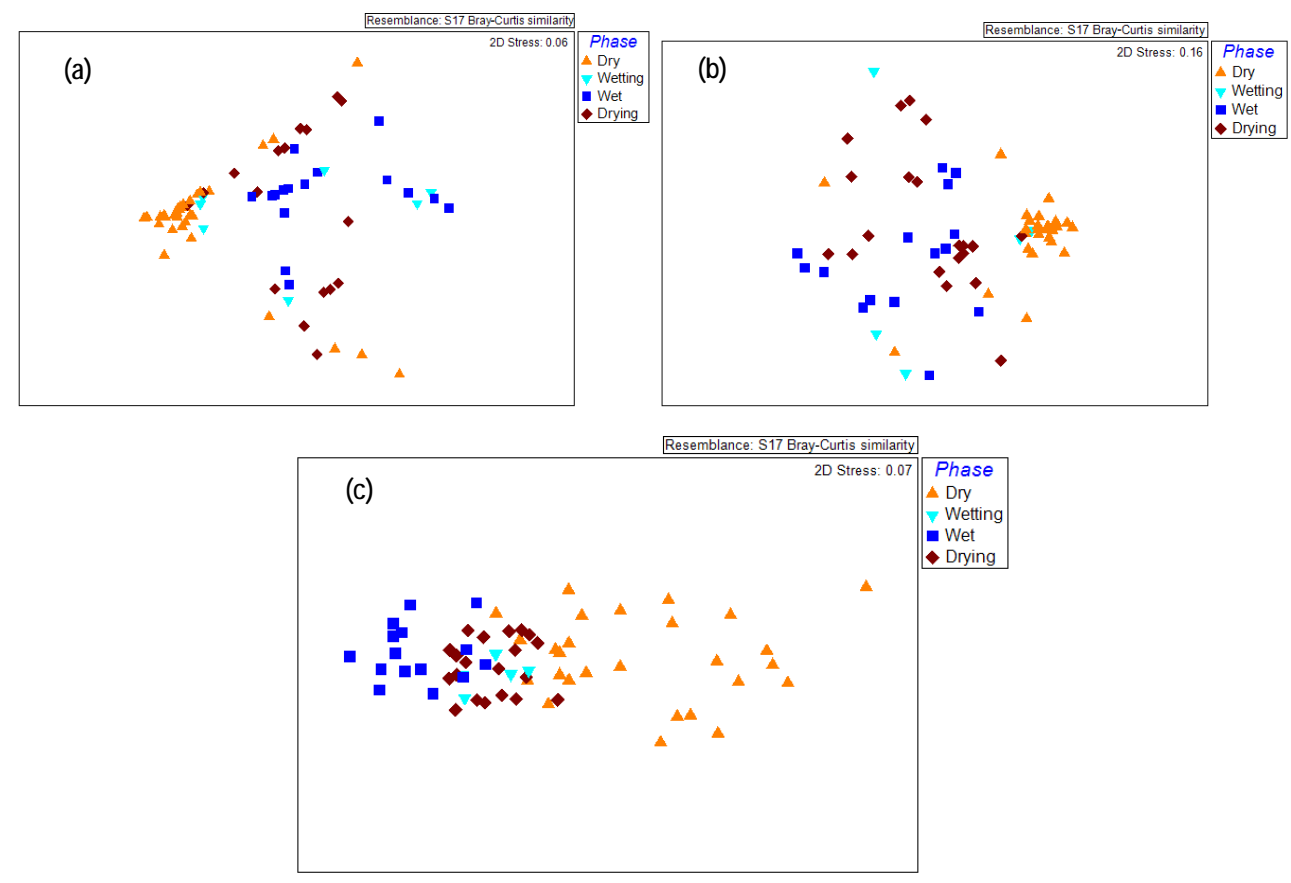

Figure 5. Nonmetric multidimensional scaling (MDS) ordinations of adaptive cycles using (a) area and quality, (b) number and directions of transitions, and (c) probability of transitions.

The observed pattern of the direction of transitions also followed the hypothesised adaptive-cycle model. In all events there was a significant difference in the number of two-way transitions among the wetting, wet, drying and dry phases of the adaptive cycle (Table 2). However, in all events there was no significant difference in the number of one-way transitions among the phases in any of the events (Table 2). In all events, both one-way and two-way transitions occurred in the dry, wetting, wet and drying phases (Fig. 7). The wet phase was more dynamic, with a higher frequency of oneway and two-way transitions, which was not hypothesised in the model. Overall, one-way transitions were more prevalent in the dry phase and two-way transitions in the wet phase (Fig. 6). The ratio of one-way to two-way transitions in the dry phase was 0.42 , significantly higher (Student's $t$ test: $p<0.001)$ than the ratios of the other phases $(0.27$ for the wetting phase, 0.09 for the wet phase, and 0.25 for the drying phase).

Ordination based on one-way and two-way transitions revealed little separation of the wetting-, wet- and drying-phase images, but a separation of dry-phase images (Fig. 5b). The dry-phase images are clumped in multivariate space, whereas the wetting, wet- and drying-phase images are more dispersed (Table 3). The greatest distance among centroids is between the dry phase and the wetting, wet and drying phases (Table 4). This suggests that the wetting, wet and drying phases are more similar to each other than to the dry phase (Table 4).
Table 4. Centroid distances between different adaptive-cycle phases using NDVI class area and quality, number and direction of NDVI class transitions, and probability of NDVI class transition data.

\begin{tabular}{|c|c|c|c|c|}
\hline \multirow[b]{2}{*}{ Data type } & \multicolumn{4}{|c|}{ Group centroid distances } \\
\hline & Dry & Wetting & Wet & Drying \\
\hline \multicolumn{5}{|c|}{ Area and quality } \\
\hline Dry & - & & & \\
\hline Wetting & 28.33 & - & & \\
\hline Wet & 39.70 & 12.52 & - & \\
\hline Drying & 30.34 & 10.60 & 13.70 & - \\
\hline \multicolumn{5}{|c|}{ Number and direction of transitions } \\
\hline Dry & - & & & \\
\hline Wetting & 37.76 & - & & \\
\hline Wet & 48.15 & 25.78 & - & \\
\hline Drying & 40.82 & 23.32 & 13.42 & - \\
\hline \multicolumn{5}{|c|}{ Probability of transitions } \\
\hline Dry & - & & & \\
\hline Wetting & 27.37 & - & & \\
\hline Wet & 39.59 & 15.96 & - & \\
\hline Drying & 27.36 & 1.71 & 15.96 & - \\
\hline
\end{tabular}



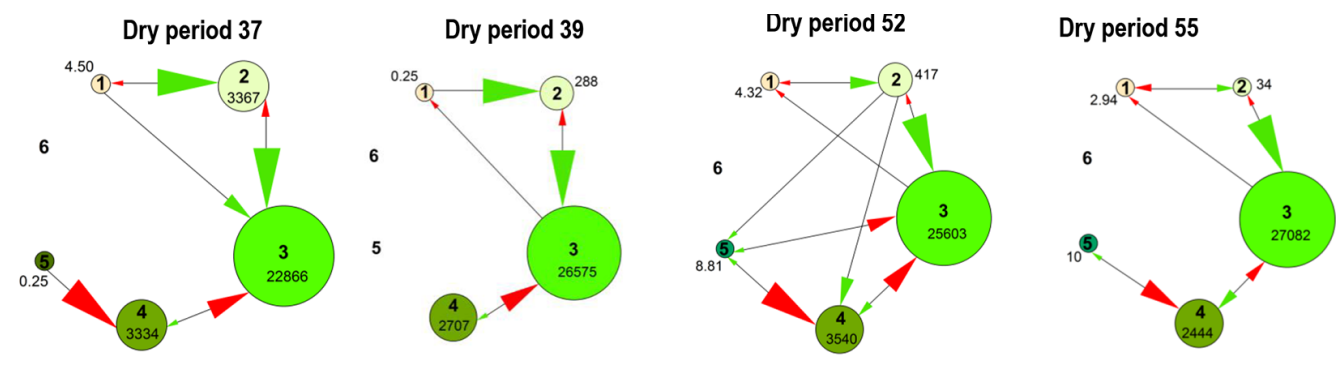

\section{Wetting period 6}

Wetting period 24
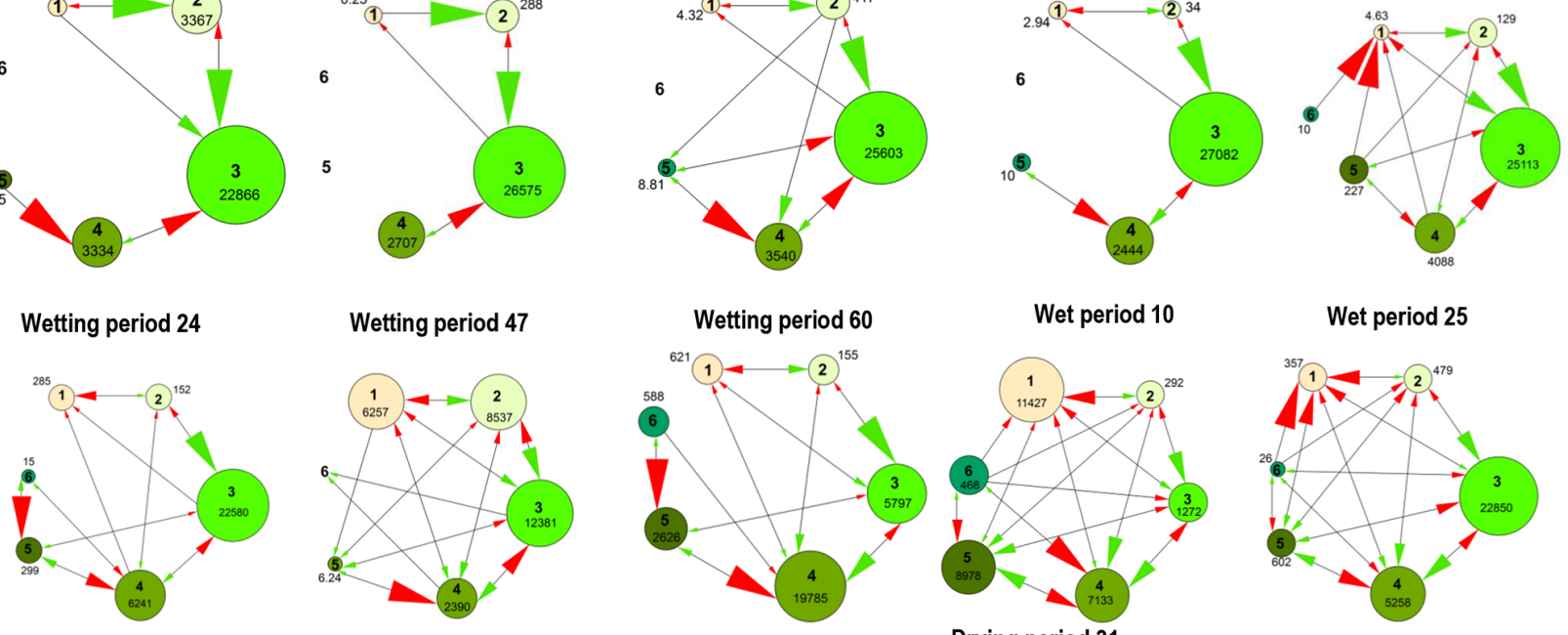

Drying period 31
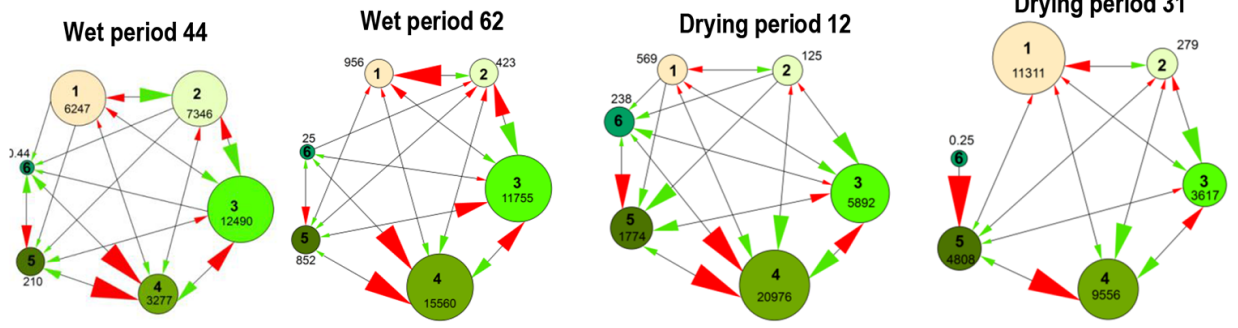

LEGEND

Wet period 25
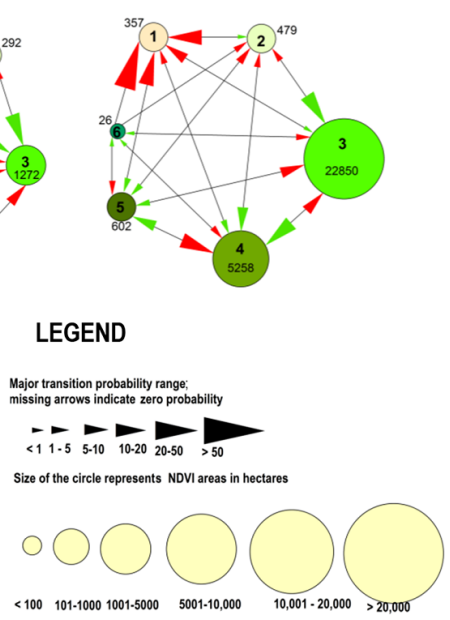

Figure 6. An example Markovian transition model of change between NDVI Classes 1-6 in the dry, wetting, wet and drying phases of floodplain inundation. The area of floodplain in each NDVI class is shown by differently sized circles and labelled with area (ha). Arrows identify the changes between NDVI classes, with red arrows indicating decrease and the green arrows indicating increase in NDVI classes. The size of the arrowhead indicates the probability of change among NDVI classes. Periods are explained in Table 1.

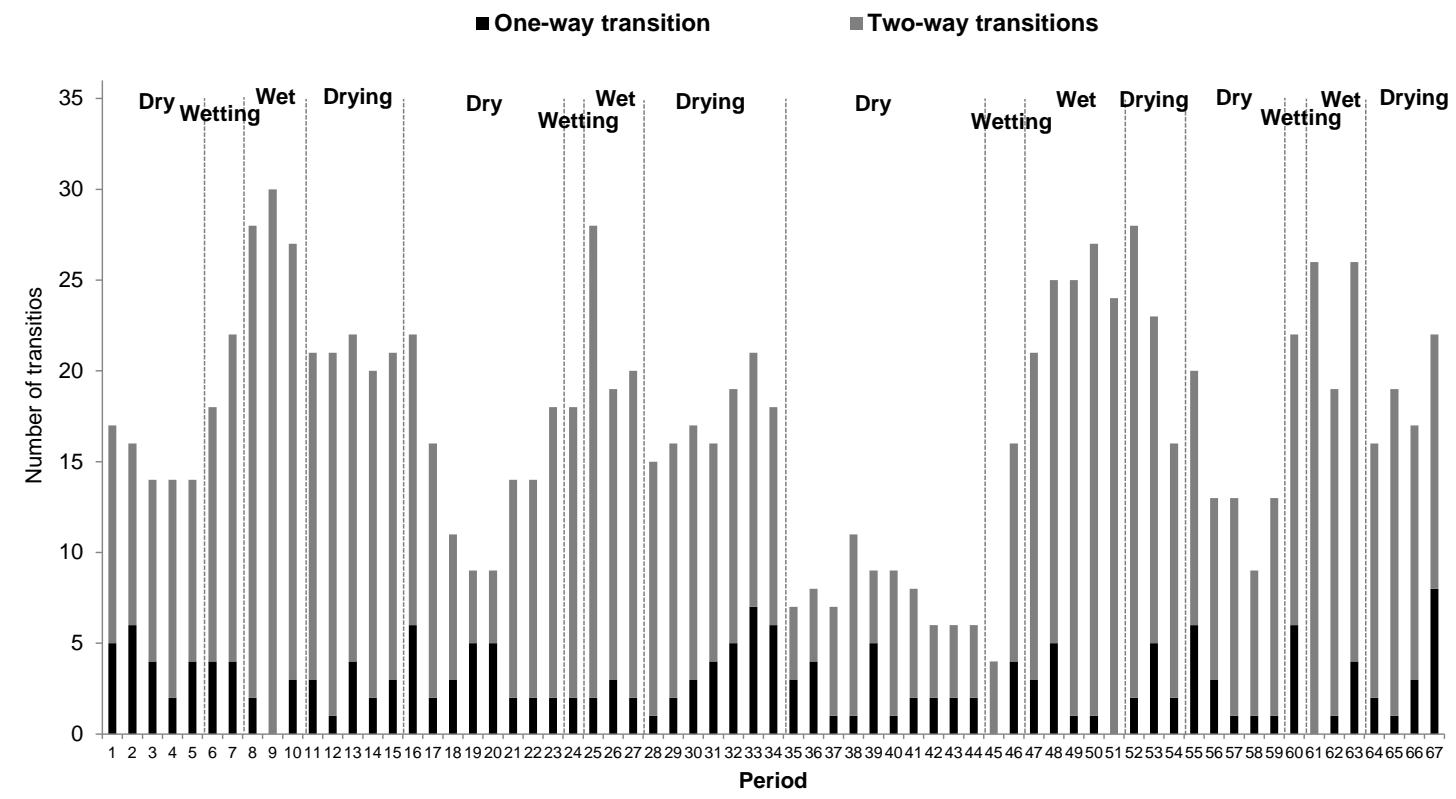

Figure 7. Total number of transitions and one-way and two-way transitions between NDVI classes in the adaptive-cycle phases. Periods are explained in Table 1. 

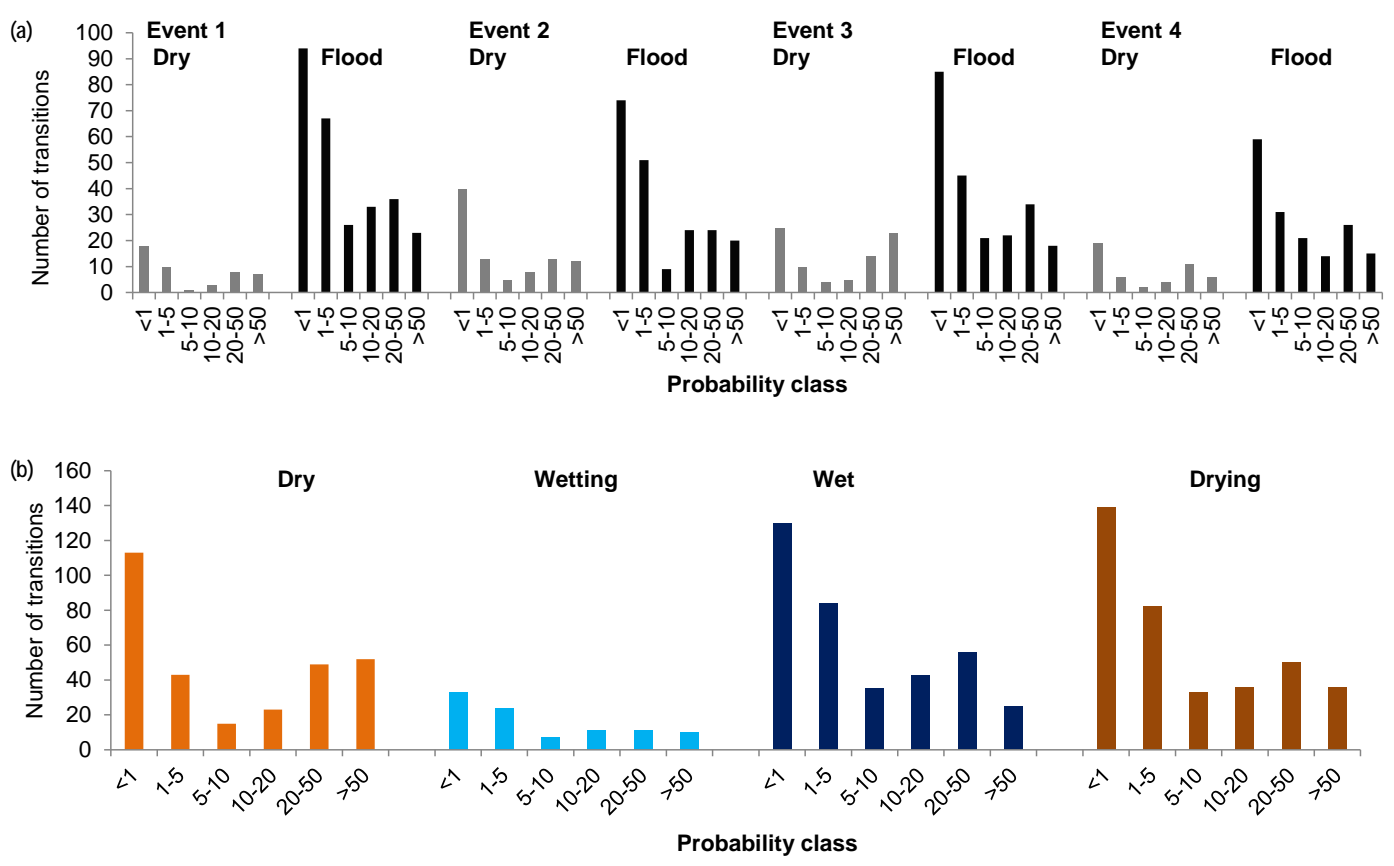

Figure 8. The distribution of probability transition classes in (a) events divided into flood and dry components and (b) the dry, wetting, wet and drying adaptive-cycle phases.

\subsection{Probability of NDVI class transitions through the adaptive-cycle phases}

Distributions of the probability of NDVI class transitions were bimodal for each flood event (Fig. 8a) and each phase of the adaptive cycle (Fig. 8b). All distributions had a primary mode in the $<1 \%$ probability class and a secondary mode occurring in the $10-20,20-50 \%$ or $>50 \%$ probability class. There were differences in the bimodality of the probability of NDVI class transitions between the dry, wetting, wet and drying phases (Fig. 8b).

In particular, the dry phase was characterised by a primary mode in $<1 \%$ and a secondary mode in the 20-50 and $>50 \%$ probability class (Fig. $8 \mathrm{~b}$ ). Combined, the number of transitions in the $20-50$ and $>50 \%$ probability classes was equivalent to that recorded in the $<1 \%$ probability class. Thus, the probability of NDVI class transitions in the dry phase is dominated by a higher frequency of both low- and high-probability transitions. This contrasts with the wetting phase, where the distribution of NDVI class transitions was weakly platykurtic in nature, with a primary mode at $<1 \%$ and a weaker secondary mode at $10-20 \%$, suggesting that the probability of class transitions is dominated by lowerprobability transitions (Fig. 8b). The distribution of the probability of NDVI class transitions in the wet and drying phases was similar to each other but different to that of the dry and wetting phases (Fig. 8b). These distributions had a dominant primary mode at $<1 \%$ and a secondary mode at $20-50 \%$. These observed class transitions were as was hypothesised for the wetting, wet and drying phases but not for the dry phase.

In contrast to the other types of data, ordination based on transition probability classes revealed dispersion of the dryphase images and clumping of the wetting-, wet- and dryingphase images (Table 3 and Fig. 5c). In addition, the greatest distance among centroids was between the dry phase and the wetting, wet and drying phases (Table 4). The wetting-, wetand drying-phase centroids were closer to each other in multivariate space (Table 4), but the centroid distances between the drying and wetting phase were similar (Table 4).

\subsection{Diversity of vegetation productivity through the adaptive-cycle phases}

The diversity of NDVI classes among the wetting, wet, drying and dry phases followed the hypothesised adaptive-cycle model. In all four events there was an increase in NDVI class diversity from the wetting to the wet phase followed by a decrease in the drying phase, with the lowest diversity occurring following the dry phase (Fig. 9). In most events there was a significant difference in NDVI class diversity among the wetting, wet, drying and dry phases (Table 2). In the dry phase, diversity was relatively low, averaging 0.55 (range: 0 . 16 to 1.24 ), while the wetting phase had an average diversity of 1.02 (range: 0.65 to 1.56 ). For comparison, the wet phase had the highest average diversity of 1.21 (range: 0.98 to 1.40 ) and the drying phase had an average diversity of 1.08 (range: 0.57 to 1.45 ). 
Table 5. Differences in NDVI class area and quality, number and direction of NDVI class transitions, probability of NDVI class transitions, and NDVI class diversity among events for each adaptive phase. NS: not significant $(p>0.05)$. No test: replication unavailable for a test.

\begin{tabular}{lcccc}
\hline & \multicolumn{4}{c}{$p$ value } \\
\cline { 2 - 5 } Data type & Dry & Wetting & Wet & Drying \\
\hline Area and quality & & & & \\
Total area of active NDVI & 0.008 & NS & 0.015 & 0.017 \\
NDVI Class 2 & 0.036 & NS & 0.006 & 0.011 \\
NDVI Class 3 & NS & NS & 0.016 & NS \\
NDVI Class 4 & NS & NS & NS & 0.010 \\
NDVI Class 5 & $<0.001$ & NS & 0.014 & 0.008 \\
NDVI Class 6 & NS & NS & NS & 0.020 \\
\hline Number and direction of transitions & & & & \\
\hline One-way transitions & 0.046 & No test & NS & NS \\
Two-way transitions & 0.019 & No test & NS & 0.007 \\
Total transitions & 0.001 & No test & NS & 0.017 \\
\hline Probability of transitions (\%) & & & & \\
\hline Number of transition with probability $<1$ & 0.002 & No test & NS & NS \\
Number of transition with probability 1 to 5 & 0.028 & No test & NS & NS \\
Number of transition with probability 5 to 10 & NS & No test & NS & NS \\
Number of transition with probability 10 to 20 & NS & No test & NS & NS \\
Number of transition with probability 20 to 50 & NS & No test & NS & NS \\
Number of transition with probability $>50$ & NS & No test & NS & NS \\
\hline Diversity & & & & \\
\hline Diversity of NDVI class area & NS & NS & NS & 0.011 \\
\hline
\end{tabular}

\subsection{Vegetation productivity among flood events}

Despite the occurrence of adaptive phases in all four events, the size of each flood had some effect on aspects of vegetation productivity in some of the adaptive-cycle phases. There was a significant difference in total NDVI area and NDVI quality among events in the dry, wet and drying phases but not in the wetting phase (Table 5). However, these differences among events did not apply to all NDVI quality classes (Table 5). Significant differences in the direction of NDVI class transitions occurred among events in the dry and drying phases but not in the wet phase (Table 5). In contrast, there were generally no significant differences in probability of NDVI class transitions among events in any of the phases (Table 5). Diversity only differed among events in the drying phase (Table 5). Thus, a positive relationship between flood size and the area of floodplain vegetation productivity was observed in the Narran floodplain. However, all floods had a similar response in terms of the relative quality of NDVI and the nature of changes in floodplain vegetation productivity through each of the adaptive-cycle phases.

\section{Discussion}

There is limited empirical evidence demonstrating the application of adaptive cycles (Scheffer, 2009), despite the widespread acceptance of resilience theory and the adaptivecycle model of ecosystem change (Holling, 1986; Holling and Gunderson, 2002). This study showed that the response of vegetation productivity to wetting and drying in the semiarid Narran floodplain repeatedly followed an adaptive cycle in each of four flood events. Vegetation productivity response followed the hypothesised adaptive-cycle phases of wetting, wet, drying and dry corresponding to a cycle of conservation, release, reorganisation and exploitation. Thus, adaptive cycles are a sound representation of the dynamics of floodplain vegetation response to flooding and drying. Adaptive cycles highlight the complexity of vegetation productivity responses to flooding and drying in contrast to the simpler boom-bust, or related state-transition, models that form the current understanding of semi-arid floodplains (Walker et al., 1995). Boom-bust and state-transition models of floodplain productivity emphasise that maximum productivity occurs when water is added to a floodplain in flood events (Bunn et al., 2006). Under an adaptive-cycle model the presence or absence of water remains a key driver of vegetation productivity. However, vegetation productivity is not confined to periods of floodplain inundation only (cf. Parsons and Thoms, 2013) but occurs regardless of the presence or absence of surface water and differs throughout floodplain inundation as it cycles through wetting, wet, drying and dry phases. 


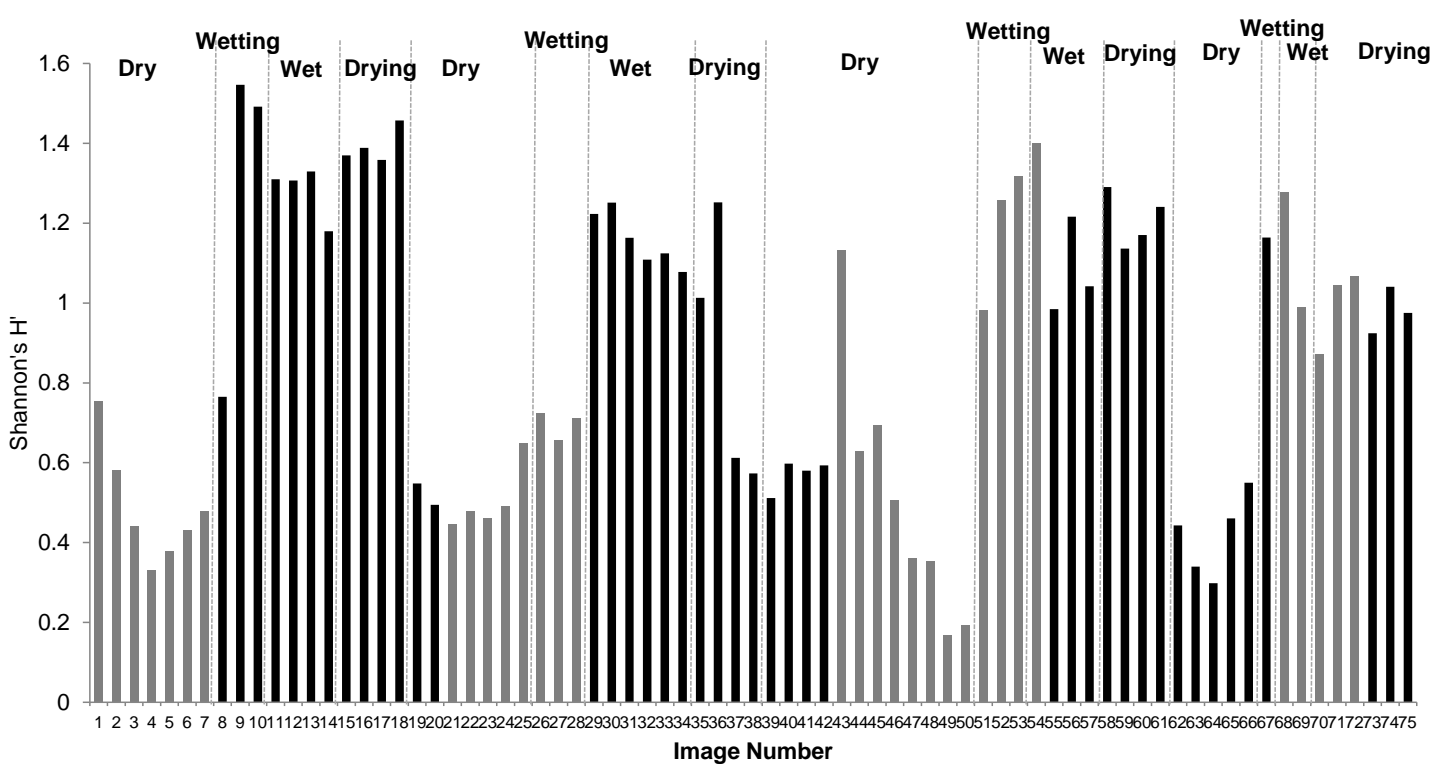

Figure 9. Shannon-Wiener Diversity Index of NDVI class area in the dry, wetting, wet and drying adaptive-cycle phases. Image numbers are explained in Table 1.

In all four events, observed floodplain vegetation productivity responses matched those hypothesised in the adaptivecycle model derived from one event (Thapa et al., 2016). The area of vegetation productivity increased in the dry and drying phases and decreased in the wetting and wet phases. The quality of vegetation productivity was also as hypothesised, with higher-quality vegetation productivity in the wet and wetting phases, lower-quality productivity in the drying phase and lowest-quality productivity in the dry phase. The maximum number of transitions between NDVI classes occurred in the wet phase and was dominated by two-way transitions, as hypothesised. The dry phase had the lowest number of transitions and was dominated by oneway transitions, as hypothesised. The distribution of probability transitions was bimodal in all phases, also as hypothesised, but the degree of bimodality differed between phases. The wetting, wet and drying phases were dominated by smaller-probability class changes (i.e. more frequent smaller-magnitude changes), whereas in the dry phase, higher-probability changes (i.e. higher-magnitude changes) were more prominent, and this was not as hypothesised. Diversity also followed the hypothesised adaptive-cycle model with a high diversity of NDVI classes in the wet phase, decreasing through the drying phase to be lowest in the dry phase. These recurrent patterns of vegetation productivity through the phases of the adaptive cycle demonstrate that the effects of floodplain flooding and drying are consistently reflected in vegetation response. One of the tenets of the theory of adaptive cycles is repetition through phases of conservation, release, reorganisation and exploitation, where one phase builds the conditions that influence the movement of the system into the next phase (Holling and Gunderson,
2002). The movement of Narran floodplain vegetation productivity through the adaptive-cycle phases is influenced by the conditions of flooding and drying associated with a hydrological driver of ecosystem change.

Although the adaptive cycle repeated over four events, some differences in vegetation response were observed among flood events. The hydrological character of the four events varied in terms of the area of floodplain inundation and translated into differences in the duration of adaptivecycle phases among events. In particular, the events differed with regard to the duration of the wet and wetting phases but not of the dry phase, which was greater than 12 months for each event. In low-gradient floodplains there is a general positive relationship between discharge and the area of floodplain inundation (Murray et al., 2006), where larger discharges inundate more floodplain area and therefore connect a greater area under flood (Mertes et al., 1995; Hughes, 1997). The hydrological character of flood events, that is the timing, magnitude and duration of floodplain inundation, is consistently identified as a prominent influence on landscape patterns of floodplain vegetation (Mertes et al., 1995; Capon, 2005; Ward et al., 2014). The results of this study revealed an inconsistent influence of flood size on vegetation productivity response through the adaptive-cycle phases. The larger flood (e.g. Event 1) had a greater area of floodplain inundation (Fig. 3) but a smaller area of NDVI (Fig. 4). Thus, smaller floods, which are associated with a smaller area of floodplain inundation, had larger areas of NDVI. Differences in NDVI quality, probability and direction of change and diversity among events were inconsistent and changed according to adaptive-cycle phase. Landscape patterns of floodplain vegetation productivity can be influenced 
by a range of hydro-geomorphic factors including hydrology (Sims and Thoms, 2002), soil character (Reid at al., 2011) and floodplain morphology (Scown et al., 2016). In a series of experiments designed to test the influence of different flooding and drying regimes on floodplain vegetation, Webb et al. (2006) demonstrated that prolonged waterlogging of floodplain soils can inhibit vegetation recruitment and productivity. Thus, longer-duration flood events may suppress floodplain vegetation productivity in the wet phase. By comparison, larger-scale variations in the nutrient status of floodplain soils have been inferred to influence vegetation productivity across floodplains whereby areas of elevated nutrients are associated with more productive vegetation and faster vegetation productivity response to flooding (Sims and Thoms, 2002; Reid et al., 2011). However, the systematic variation of soil nutrient concentrations from west to east across the Narran floodplain, which is a legacy of past geomorphic processes (Rayburg et al., 2006), suggests the minimal influence of soil nutrients on the landscape pattern of vegetation productivity response.

The environmental processes influencing vegetation productivity response through the wetting, wet, drying and dry adaptive-cycle phases in the Narran floodplain can only be hypothesised at present. Nonetheless, understanding patterns at multiple levels of organisation is an essential first step in deciphering the relationships between ecosystem pattern and process (Turner, 1989). The new philosophy of science (Pickett at al., 1994) emphasised the explanation of structures and patterns rather than focusing solely on proving causality using a falsification approach. Experiments can be conducted on plant ecophysiology and inundation interactions to understand the causal mechanisms driving floodplain vegetation productivity responses through the adaptive-cycle phases. However, floodplains are complex systems and vegetation responses to inundation may have multicausal, selfemergent and hierarchically organised properties that can never be fully deciphered with a reductionist approach. Interdisciplinary floodplain research requires information on both the complexity of patterns on multiple scales and detailed experimental studies to increase understanding about the nature of change and the potential influence of multiple drivers on patterns of change.

Studying resilience is about characterising and understanding change in complex systems (Gunderson and Pritchard, 2002; Walker and Salt, 2012). Ecologically, resilience can be defined as the capacity of systems to undergo change while maintaining the same fundamental structure, function and feedbacks (Holling, 1973; Holling and Gunderson, 2002; Walker and Salt, 2012). Adaptive cycles are a component of resilience theory and provide a framework for understanding how complex systems undergo change (Holling and Gunderson, 2002). The results of this study consistently demonstrated vegetation productivity change through an adaptive cycle in response to flooding and drying. Thus, this study supports the notion of Holling (1973) and
Holling and Gunderson (2002) that a resilient system fluctuates between the four phases of an adaptive cycle. A feature of an adaptive cycle is that it contains an exit point where the system might flip to a different cycle characterised by different structure, function and feedbacks (Holling, 1973; Gunderson and Pritchard, 2002). Although little is known about the exit from an adaptive cycle, exit points have been characterized as periods of marked change in the stability of key driving factors (Scheffer and Carpenter, 2003; Scheffer, 2009). When a system approaches a threshold of change, it fluctuates more, which is thought to be an indicator of an impending change in state or regime shift (Biggs et al., 2009; Scheffer, 2009). The transition between the reorganisation and exploitation phases is considered as the point in the adaptive cycle at which a system is more vulnerable to state change (Holling and Gunderson, 2002; Scheffer et al., 2001). Example state changes have been observed for lake, coral reef, forest and grassland ecosystems (Scheffer et al., 2001; Scheffer and Carpenter, 2003; Wolf et al., 2007), but it has only been hypothesised thus far that this state change occurs between the reorganisation and exploitation phases of the adaptive cycle. In the Narran floodplain, stability, rather than instability, in vegetation productivity was observed in the reorganisation and exploitation phases of the adaptive cycle. The conservation phase of the floodplain adaptive cycle was found to be the most unstable, with a greater number of transitions between NDVI classes, a greater number of two-way transitions, and transitions characterised by highfrequency or low-magnitude changes in NDVI class. The results from the Narran floodplain suggest that in contrast to theory, the exit point occurs in the conservation to release phases when the floodplain is wet, not dry. Resilience thinking may provide a useful framework with which to investigate the physical domains (water and sediment exchange) of floodplains as earth surface systems. Concepts of resilience, such as adaptive cycles and tipping points, may act as useful frameworks with which to investigate dynamic earth surface systems.

This study used the hypothesised floodplain adaptivecycle model of Thapa et al. (2016) to show that the adaptive cycle of floodplain vegetation response to flooding and drying repeated over multiple events. An adaptive-cycle model of vegetation productivity improves on current boom-bust, state and transition models for floodplains in semi-arid regions. The adaptive-cycle model acknowledges the importance of transitions between phases rather than a focus on a limited number of states - the boom (wet) or bust (dry) states. Semi-arid floodplains change naturally as a result of the feedbacks between water, sediment and vegetation on the floodplain surface but are also increasingly influenced by anthropogenic pressures that interrupt the feedbacks (Thoms, 2003). Changes in vegetation productivity could initiate structural changes in floodplain vegetation communities, with commensurate influences on floodplain sediment dynamics. An enhanced understanding of the com- 
plexity of floodplain change using an adaptive-cycle perspective will increase our ability to model and manage these valuable but fragile ecosystems in the future.

Acknowledgements. The authors thank Geoscience Australia and the United States Geological Survey for supplying Landsat images. This research was supported by a UNE International Strategic Postgraduate Scholarship.

Edited by: H. Viles

\section{References}

Anderson, M., Gorley, R., and Clarke, K.: Primer-E. PERMANOVA+ for PRIMER: Guide to software and statistical methods, Plymouth University, Plymouth, UK, 2008.

Biggs, R., Carpenter, S. R., and Brock. W. A.: Turning back from the brink: Detecting an impending shift in time to avert it, P. Natl. Acad. Sci. USA, 106, 826-831, 2009.

Bolliger, J., Wagner, H. H., and Turner, M. G.: Identifying and Quantifying Landscape Patterns, in: A Changing World. Challenges for Landscape Research, edited by: Kienast, F., Wildi, O., and Ghosh, S., Springer Science, Dordrecht, the Netherlands, 177-194, 2009.

Bunn, S. E., Thoms, M. C., Hamilton, S. K., and Capon, S. J.: Flow variability in Dryland Rivers: boom, bust and the bits in between, River Res. Appl., 22, 179-186, 2006.

Capon, S. J.: Plant community responses to wetting and drying in a large arid floodplain, River Res. Appl., 19, 509-520, 2003.

Capon, S. J.: Flood variability and spatial variation in plant community composition and structure on a large arid floodplain, J. Arid Environ., 60, 283-302, 2005.

Chander, G., Markham, B. L., and Helder, D. L.: Summary of current radiometric calibration coefficients for Landsat MSS, TM, ETM+, and EO-1 ALI sensors, Remote Sens. Environ., 113, 893-903, 2009.

Dollar, E. S. J., James, C. S., Rogers, K. H., and Thoms, M. C.: A framework for interdisciplinary understanding of rivers as ecosystems, Geomorphology, 89, 147-162, 2007.

Farina, A.: Principles and Methods in Landscape Ecology, Towards a Science of Landscape, Springer Science, Dordrecht, the Netherlands, 2006.

Fitzpatrick, A., Clarke, J. D. A., and Lane, R.: Mapping hydrological architecture beneath the lower Balonne floodplain, Queensland, Australia, Geophysical Research Abstracts, 7, 02505, 2005.

Folke, C., Carpenter, S. R., Walker, B., Scheffer, M., Chapin, T., and Rockström, J.: Resilience thinking: integrating resilience, adaptability and transformability, Ecol. Soc., 15, available at: http://www.ecologyandsociety.org/vol15/iss4/art20/ (last access: 19 January 2016), 2010.

Frazier, P. S. and Page, K. J.: Water body detection and delineation with Landsat TM data, Photogramm. Eng. Rem. S., 66, 14611468, 2000.

Gunderson, L. H. and Pritchard, L.: Resilience and Behaviour of Large-Scale Systems, Island Press, Washington, USA, 2002.

Holling, C. S.: Resilience and stability of ecological systems, Annu. Rev. Ecol. Syst., 4, 1-23, 1973.
Holling, C. S.: The resilience of terrestrial ecosystems, local surprise and global change, in: Sustainable development of the biosphere, edited by: Clark, W. C., and Munn, R. E., Cambridge University Press, Cambridge, UK, 292-317, 1986.

Holling, C. S. and Gunderson, L.: Resilience and adaptive cycles, in: Panarchy: Understanding Transformations in Human and Natural Systems, edited by: Gunderson, L. and Holling, C. S., Island Press, Washington DC, USA, 25-62, 2002.

Horner, G. J., Baker, P. J., Nally, R. M., Cunningham, S. C., Thomson, J. R., and Hamilton, F.: Mortality of developing floodplain forests subjected to a drying climate and water extraction, Global Change Biol., 15, 2176-2186, 2009.

Hughes, F. M. R.: Floodplain biogeomorphology, Prog. Phys. Geog., 21, 501-529, 1997.

Hupp, C. R.: Hydrology, geomorphology and vegetation of Coastal Plain rivers in the sout-eastern USA, Hydrol. Process., 14, 29913010, 2000.

Lillesand, T. M. and Kiefer, R. W.: Remote sensing and image interpretation, John Wiley and Sons, New York, USA, 2000.

Magurran, A. E.: Ecological diversity and its measurement, Springer-Verlag, Berlin, Germany, 1988.

Mertes, L. A. K., Daniel, D. L., Melack, J. M., Luiz, B. N., Martinelli, A., and Forsberg, B. R.: Spatial patterns of hydrology, geomorphology, and vegetation on the floodplain of the Amazon River in Brazil from a remote sensing perspective, Geomorphology, 13, 215-232, 1995.

Murray, O., Thoms, M., and Rayburg, S.: The diversity of inundated areas in semi-arid flood plain ecosystems, International Association of Hydrological Sciences, 306, 277-286, 2006.

Myeong, S., Nowak, D. J., and Duggin, M. J.: A temporal analysis of urban forest carbon storage using remote sensing, Remote Sens. Environ., 101, 277-282, 2006.

Naiman, R. J., Bechtold, J. S., Beechie, T. J., Latterell, J. J., and Van Plet, R.: A process-based view of floodplain forest patterns in coastal river valleys of the Pacific Northwest, Ecosystems, 13, 1-31, 2010.

Overton, I. C.: Modelling floodplain inundation on a regulated river: integrating GIS, remote sensing and hydrological models, River Res. Appl., 21, 991-1000, 2005.

Parsons, M. and Thoms, M. C.: Patterns of vegetation greenness during flood, rain and dry resource states in a large, unconfined floodplain landscape, J. Arid Environ., 88, 24-38, 2013.

Pickett, S. T. A., Kolasa, J., and Jones, C. G.: Ecological Understanding: The Nature of Theory and the Theory of Nature, Academic Press, San Diego, CA, USA, 1994.

Rayburg, S. and Thoms, M.: A coupled hydraulic-hydrologic modelling approach to deriving a water balance model for a complex floodplain wetland system, Hydrol. Res., 40, 364-379, 2009.

Rayburg, S., Thoms, M., and Lenon, E.: Unravelling the physical template of a terminal floodplain - wetland sediment storage system, International Association of Hydrological Sciences, 306, 304-313, 2006.

Reid, M. A., Ogden, R., and Thoms, M. C.: The influence of flood frequency, geomorphic setting and grazing on plant communities and plant biomass on a large dryland floodplain, J. Arid Environ., 75, 815-882, 2011.

Scheffer, M.: Critical Transitions in Nature and Society, Princeton University Press, Princeton, USA, 2009. 
Scheffer, M. and Carpenter, S. R.: Catastrophic regime shifts in ecosystems: linking theory to observation, Trends Ecol. Evol., 18, 648-656, 2003.

Scheffer, M., Carpenter, S., Foley, J. A., Folke, C., and Walker, B.: Catastrophic shifts in ecosystems, Nature, 413, 591-596, 2001.

Scown, M., Thoms, M., and De Jager, N. R.: Measuring spatial pattern in floodplains: A step towards understanding the complexity of floodplain ecosystems, in: River Science: Research and Applications for the 21st Century, edited by: Gilvear, D. J., Greenwood, M., Thoms, M., and Wood, P., John Wiley and Sons, UK, 239-258, 2016.

Shaikh, M., Green, D., and Cross, H.: A remote sensing approach to determine environmental flows for wetlands of the Lower Darling River, New South Wales, Australia, Int. J. Remote Sens., 22, 1737-1751, 2001.

Sims, N. C. and Thoms, M. C.: What happens when flood plains wet themselves: vegetation response to inundation on the lower Balonne floodplain, International Association of Hydrological Sciences, 276, 195-202, 2002.

Thapa, R., Thoms, M., and Parsons, M.: An adaptive cycle hypothesis of semi-arid floodplain vegetation productivity in dry and wet resource states, Ecohydrology, 9, 39-51, 2016.

Thomas, R., Bowen, S., Simpson, S., Cox, S., and Sims N.: Inundation response of vegetation communities of the Macquarie Marshes in semi-arid Australia, in: Ecosystem Response Modelling in the Murray - Darling Basin, edited by: Saintilan, N., and Overton, I., CSIRO publishing, Melbourne, Australia, 139153,2010

Thoms, M. and Parsons, M.: Patterns of vegetation community distribution in a large, semi-arid floodplain landscape, River Systems, 19, 271-282, 2011.

Thoms, M., Capon, S., Padgham, M., and Rayburg, S.: The Narran Ecosystem Project: The response of a terminal wetland system to variable wetting and drying. Final report to Murray-Darling Basin Commission. No. 40/08, Canberra, Australia, 2007.

Thoms, M. C.: Floodplain-river ecosystems: lateral connections and the implications of human interference, Geomorphology, 56, 335-349, 2003
Thoms, M. C. and Sheldon, F.: Lowland rivers: An Australian introduction, Regul. River, 16, 375-383, 2000.

Turner, M. G.: Landscape ecology: the effect of pattern on process, Annu. Rev. Ecol. Syst., 20, 171-197, 1989.

Walker, B. and Salt, D.: Resilience practice: Building capacity to absorb disturbance and maintain function, Island Press, Washington DC, USA, 2012.

Walker, B. H. and Salt, D.: Resilience Thinking. Sustaining Ecosystems and People in a Changing World, Island Press, Washington DC, USA, 2006.

Walker, K. F., Sheldon, F., and Puckridge, J. T.: A perspective on dryland river ecosystems, Regul. River, 11, 85-104, 1995.

Ward, D. P., Petty, A., Setterfield, S. A., Douglas, M. M., Ferdinands, K., Hamilton, S. K., and Phin, S.: Floodplain inundation and vegetation dynamics in the Alligator Rivers region (Kakadu) of northern Australia assessed using optical and radar remote sensing, Remote Sens. Environ., 147, 43-55, 2014.

Warwick, R. and Clarke, K.: Increased variability as a symptom of stress in marine communities, J. Exp. Mar. Biol. Ecol., 172, 215 226, 1993.

Webb, M. C., Reid, M. A., Capon, S., Thoms, M. C., Rayburg, S., and James, C. S.: Are floodplain-wetland plant communities determined by seed bank composition or inundation periods?, International Association of Hydrological Sciences, 306, 241-350, 2006.

Wen, L., Yang, X., and Saintilan, N.: Local climate determines the NDVI-based primary productivity and flooding creates heterogeneity in semi-arid floodplain ecosystem, Ecol. Model., 242, 116-126, 2012.

Weng, Q.: Land use change analysis in the Zhujiang Delta of China using satellite remote sensing, GIS and stochastic modelling, J. Environ. Manage., 64, 273-284, 2002.

Wolf, E. C., Cooper, D. J., and Hobbs, N. T.: Hydrologic regime and herbivory stabilize an alternative state in Yellowstone National Park, Ecol. Appl., 17, 1572-1587, 2007.

$\mathrm{Xu}, \mathrm{H}$.: Modification of normalised difference water index NDWI to enhance open water features in remotely sensed imagery, Int. J. Remote Sens., 27, 3025-3033, 2006. 